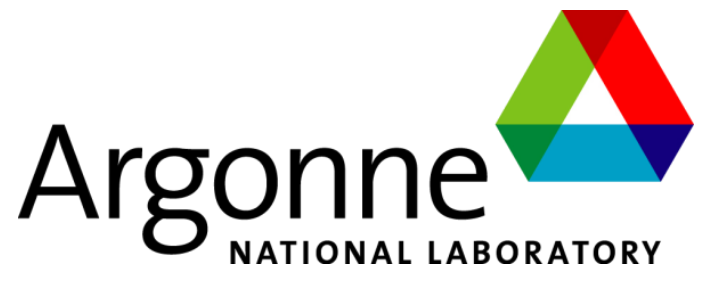

ANL-19/22

\title{
CFD Estimation of Truck Induced Wind Gusts on Variable Message Signs
}

Nuclear Science and Engineering Division 


\section{About Argonne National Laboratory}

Argonne is a U.S. Department of Energy laboratory managed by UChicago Argonne, LLC under contract DE-AC02-06CH11357. The Laboratory's main facility is outside Chicago, at 9700 South Cass Avenue, Argonne, Illinois 60439. For information about Argonne and its pioneering science and technology programs, see www.anl.gov.

\section{DOCUMENT AVAILABILITY}

Online Access: U.S. Department of Energy (DOE) reports produced after 1991 and a growing number of pre-1991 documents are available free at OSTI.GOV

(http://www.osti.gov/), a service of the U.S. Dept. of Energy's Office of Scientific and

Technical Information

\section{Reports not in digital format may be purchased by the public from the} National Technical Information Service (NTIS):

U.S. Department of Commerce

National Technical Information Service

5301 Shawnee Rd

Alexandra, VA 22312

www.ntis.gov

Phone: (800) 553-NTIS (6847) or (703) 605-6000

Fax: (703) 605-6900

Email: orders@ntis.gov

Reports not in digital format are available to DOE and DOE contractors from the Office of Scientific and Technical Information (OSTI):

U.S. Department of Energy

Office of Scientific and Technical Information

P.O. Box 62

Oak Ridge, TN 37831-0062

www.osti.gov

Phone: (865) 576-8401

Fax: (865) 576-5728

Email: reports@osti.gov

\section{Disclaimer}

This report was prepared as an account of work sponsored by an agency of the United States Government. Neither the United States Government nor any agency thereof, nor UChicago Argonne, LLC, nor any of their employees or officers, makes any warranty, express or implied, or assumes any legal liability or responsibility for the accuracy, completeness, or usefulness of any information, apparatus, product, or process disclosed, or represents that its use would not infringe privately owned rights. Reference herein to any specific commercial product, process, or service by trade name, trademark, manufacturer, or otherwise, does not necessarily constitute or imply its endorsement, recommendation, or favoring by the United States Government or any agency thereof. The views and opinions of document authors expressed herein do not necessarily state or reflect those of the United States Government or any agency thereof, Argonne National Laboratory, or UChicago Argonne, LLC. 


\section{CFD Estimation of Truck Induced Wind Gusts on Variable Message Signs}

prepared by

C. Bojanowski, S.A. Lottes, and M.A. Sitek

Nuclear Science and Engineering Division, Argonne National Laboratory

July 2019 


\section{Table of Contents}

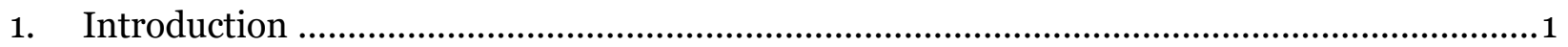

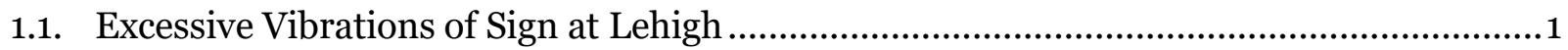

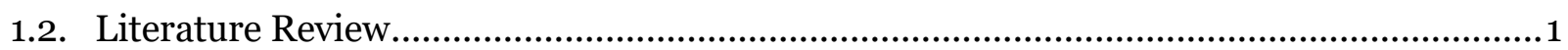

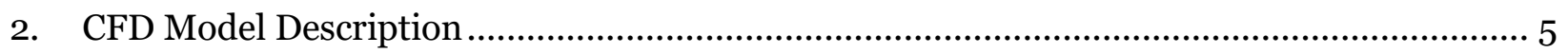

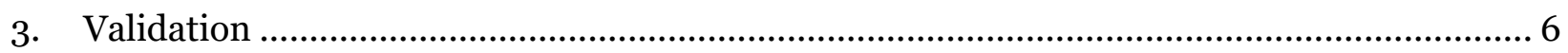

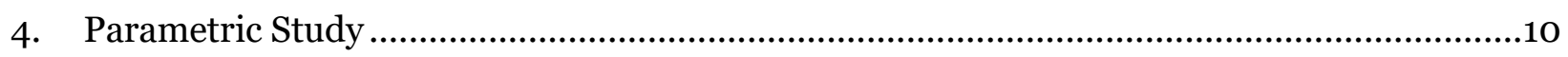

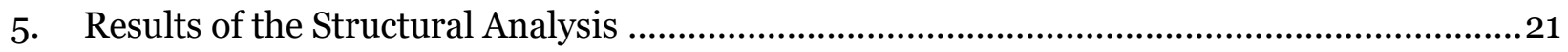

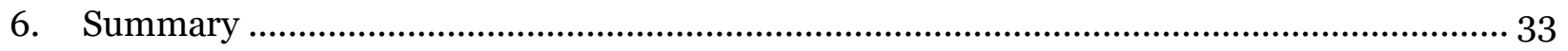

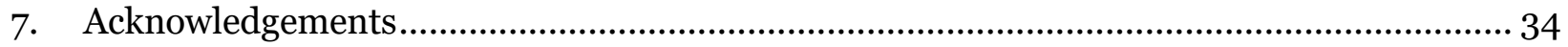

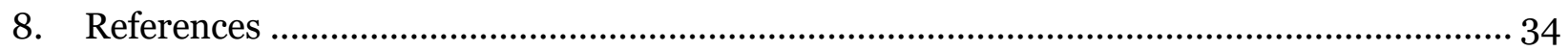




\section{List of Figures}

Figure 1-1: Shape of the impulse function assumed by [5] ................................................... 2

Figure 1-2: Typical truck induced gust pressure history by [7] …....................................... 3

Figure 2-1: CFD model geometry with interfaces used in sliding mesh motion ......................... 5

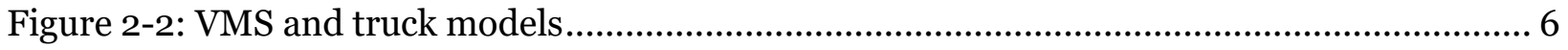

Figure 3-1: A model of European type trucks with a flat and boxy shape of the cabin .................7

Figure 3-2: Profile of the air velocities around the truck when the truck box is set in motion .......7

Figure 3-3: Time history of the force acting a plate located $1.1 \mathrm{~m}$ above the truck which is

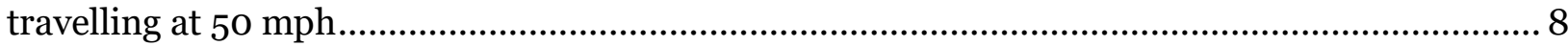

Figure 3-4: Time history of the force acting a plate located $1.1 \mathrm{~m}$ above the truck which is

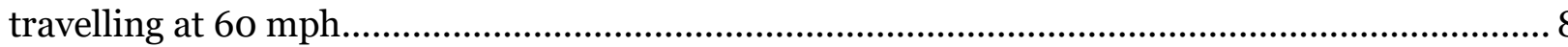

Figure 3-5: Time history of the force acting a plate located $1.37 \mathrm{~m}$ above the truck which is

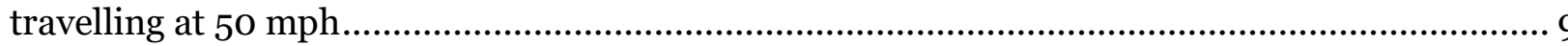

Figure 3-6: Time history of the force acting a plate located $1.37 \mathrm{~m}$ above the truck which is

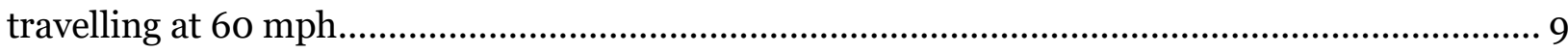

Figure 4-1: Trucks without and with over cab flow diverter or non-streamlined and streamlined

Figure 4-2: Positions of the truck corresponding to the peaks in the pressure history ............... 11

Figure 4-3: Pressure distribution on the sign surface at the time when local negative peaks occur .12

Figure 4-4: Pressure history on the front panel of the sign for simulations with streamlined truck and different velocities.

Figure 4-5: Pressure history on the front panel of the sign for simulations with non-streamlined truck and different velocities

Figure 4-6: Pressure history on the bottom panel of the sign for simulations with streamlined truck and different velocities

Figure 4-7: Pressure history on the bottom panel of the sign for simulations with nonstreamlined truck and different velocities .14

Figure 4-8: Dependency of the pressure on the truck speed. 15 
Figure 4-9: Pressure history on the front panel of the sign for simulations with non-streamlined truck and different sign height .16

Figure 4-10: Pressure history on the bottom panel of the sign for simulations with nonstreamlined truck and different sign height..... .16

Figure 4-11: Dependency of the pressure on the sign height (add $21 \mathrm{ft}$ and the streamlined truck), change sign height to clearance

Figure 4-12: Geometry of the TFHRC sign and its location over the highway lanes. .18

Figure 4-13: Worst case scenario analyzed - two trucks passing simultaneously under the sign.18

Figure 4-14: Comparison of the pressure histories on the frontal panel due to different truck configuration under the sign

Figure 4-15: Comparison of the pressure histories on the bottom panel due to different truck configuration under the sign

Figure 4-16: Pressure history on the sign frontal panel due to $10 \mathrm{mph}$ head wind and passage of a two trucks under the sign. 20

Figure 4-17: Pressure history on the sign bottom panel due to $10 \mathrm{mph}$ head wind and passage of a two trucks under the sign. . .21

Figure 5-1: Eigenmodes for the TFHRC sign model 22

Figure 5-2: Free vibration history of the cantilever tip (a) in the $\mathrm{X}$ direction and (b) in the Z direction due to gravity and forward force impulse (X direction).

Figure 5-3: FFT of the free vibration history of the cantilever tip (a) in the X direction (b) the Z direction due to gravity and forward force impulse (X direction).

Figure 5-4: Free vibration history of the cantilever tip (a) in the $\mathrm{Z}$ direction and (b) in the $\mathrm{X}$ direction due to gravity and pull down impulse (X direction) .

Figure 5-5: FFT of the free vibration history of the cantilever tip (a) in the Z direction and (b) in the $\mathrm{X}$ direction due to gravity and pull down force impulse (X direction)..... 26

Figure 5-6: Free vibration history of the cantilever tip (a) in the $\mathrm{Z}$ direction (b) in the $\mathrm{X}$ direction due to truck passage.

Figure 5-7: FFT of the free vibration history of the tip (a) in the $\mathrm{Z}$ direction (b) in the $\mathrm{X}$ direction due to truck passage. 28

Figure 5-8: Vibration history of the cantilever tip in $\mathrm{Z}$ direction caused by passage of one truck

Figure 5-9: Vibration history of the cantilever tip in $\mathrm{Z}$ direction caused by passage of three trucks (a) no damping (b) $1 \%$ of critical damping 30 
Figure 5-10: Typical pressure history acting on one element of front panel coming from combined load from 20 trucks passing under the sign ..........................................................31

Figure 5-11: Vibration history of the cantilever tip in $\mathrm{Z}$ direction caused by passage of twenty trucks (a) simulation without structural damping (b) with $1 \%$ of critical damping................... 32

Figure 5-12: Vibration history of the cantilever tip in $\mathrm{Z}$ direction caused by passage of six trucks and $10 \mathrm{mph}$ head wind................................................................................................. 33 


\section{List of Tables}

Table 1: Design pressure values proposed by [8] ............................................................... 4

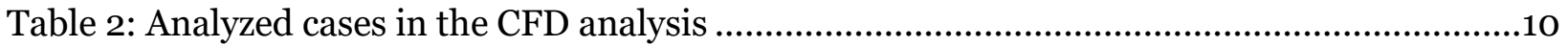




\section{Introduction}

\subsection{Excessive Vibrations of Sign at Lehigh}

Cantilevered highway Variable Message Signs (VMS, also referred to as CMS, Changeable Message Signs, in latest design specifications [1]) are potentially vulnerable to vibration caused by gusts from wind or that from truck-induced air flow.

An example of such a vibration scenario was a VMS on State Route 17 in northern New Jersey, which was reported to experience large amplitude vertical displacements at the end of the cantilever. Reported vibration displacements ranged from the neighborhood of one to two feet to approximately four feet at the tip of the cantilever. This prompted the New Jersey Department of Transportation to take down the VMS and to support the structure to protect the safety of motorists [1]. At the time of the New Jersey State Route 17 VMS vibration episodes, the AASHTO Standard Specifications for Structural Supports for Highway Signs, Luminaires, and Traffic Signals [3] (referred to as Standard Specifications hereinafter) did not offer much guidance in the design for fatigue. It was also limited in instructions for VMS supporting structures, which might have produced some faulty designs. The sixth edition of the Standard Specifications indicated that the vibration problem is commonly associated with a large projected area in the horizontal plane and a vertical gust pressure created by truck passage under the VMS [4]. An equivalent static gust pressure from trucks, PTG, is given for design purpose. A drag coefficient of 1.7 associated with the truck velocity VT is used in the calculation of PTG with an indication that it is an interim value before more research is completed to obtain a better coefficient.

The study presented in this report was done to gain a better understanding of the aerodynamic properties of VMS and supporting structures, the dynamic characteristics of truck-induced gust pressure, and the potential for wind-truck-structure interaction that may produce significant vibration episodes for the VMS structures.

\subsection{Literature Review}

Research on this subject dates back to the late 1970's, although the focus was on regular cantilever signs and not VMS, which were not in use at that time. Nonetheless, for the purpose of finding the pressure on the surfaces of any of these signs, they can be treated the same way. Although a lot more work has been performed in the area of highway sign vibration, here the focus is on the part of it that pertains to the analysis of pressure due to passing trucks.

The American Association of State Highway and Transportation Officials lists four types of wind fatigue design loads in the 2001 Standard Specifications for Structural Supports for Highway Signs, Luminaries, and Traffic Signals: galloping, vortex shedding, natural wind gusts, and truck induced gusts (also known as buffeting). These design loads are included in order to "avoid largeamplitude vibrations and to preclude the development of fatigue cracks at various connection points and at other critical locations" [5]. 
The first thorough report on this subject was published by Creamer in 1979 [6]. It covered experimental testing of three cantilevered structures instrumented with strain gauges on a sign supporting truss. The response of the signs to excitation of sign vibration in the horizontal and vertical directions was analyzed to estimate the natural frequencies of the signs and the damping ratio (which varied between $0.49 \%$ to $0.70 \%$ of critical damping for vertical motion and from $0.57 \%$ to $0.77 \%$ of critical damping for horizontal motion). The pressure acting on the sign surfaces and the light fixtures wasn't analyzed directly. It was back calculated from the measured strains with the assumption of a triangular impulse function with duration of 0.375 seconds and a peak of $1.23 \mathrm{psf}(58.89 \mathrm{~Pa})$ at 0.125 seconds, as shown in Figure 1-1. A linear decrease of pressure with the height was assumed. The values for the impulse function were adjusted until calculated member forces matched the forces obtained based on strains measured in the field tests.
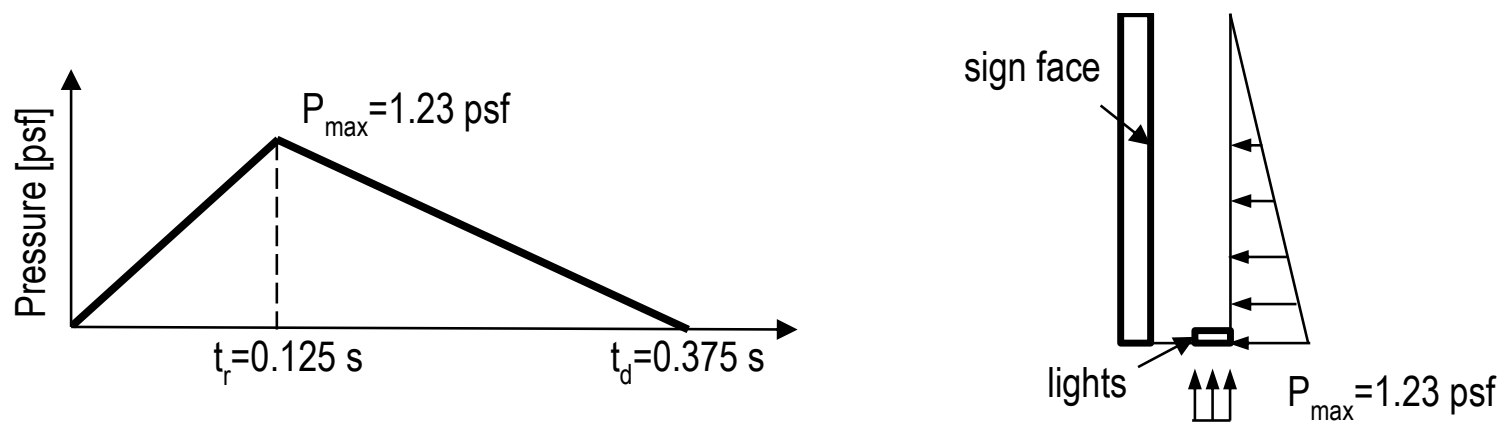

Figure 1-1: Shape of the impulse function assumed by [6]

Another study was conducted by researchers at North Carolina State University in Raleigh and concerned vibrations of four cantilevered highway sign structures [7]. The work consisted of field testing as well as wind tunnel modeling. In the field whole signs were investigated. In the wind tunnel testing, the investigation focused primarily on the trusses without the sign plate. The truss showed high susceptibility to vortex shedding induced vibrations. When an attempt was made to attach the sign plate, the wind tunnel couldn't develop high enough wind speed to induce similar vibrations. Finite element analysis was also conducted aiming to study the vibrations of the sign caused by vortex shedding induced loading. It indicated that the stresses in the structure were negligible. Buffeting wind response was also tested with a fluctuating component of the wind velocity formed by a sine function with frequencies that ranged from $0.35 \mathrm{~Hz}$ to $9.1 \mathrm{~Hz}$, covering several of the first natural frequencies of the sign. The report suggested that this load may cause large stresses in the structure.

One of the cantilevered highway sign structures in the field was instrumented with hot film anemometer patches to investigate truck-induced gust loading. The researchers determined that the maximum pressure recorded on the sign due to truck-induced gusts was $1.41 \mathrm{psf}$ (67.5 Pa). It was concluded that both box-type medium duty trucks and large semi/tractor-trailer trucks produced a similar response on the cantilevered highway sign structure. The report concluded from both the experimental testing and analytical modeling that the vibrations of the cantilevered highway sign structure due to truck-induced gusts did not result in stress levels that would damage the structure. The experimental testing also determined aerodynamic damping in the 
horizontal mode of vibration to be $1.17 \%$ of critical and in the vertical mode to be $0.58 \%$ of critical damping.

The study by Cook [8] initiated by Florida DOT describes one of the most extensive experiments to date, determining the magnitude, direction, and frequency of truck-induced gust pressure distributions on VMS. In that work, pressure transducers and pitot tubes were instrumented on an existing bridge over an interstate highway. The testing apparatus could be moved up and down what allowed for measurement of the pressure gradients of the on the sign. The researchers collected readings from 23 random trucks with the apparatus at an elevation of $17 \mathrm{ft}(5.2 \mathrm{~m})$ above the road surface. To determine the vertical profile of the pressure variation, four readings were recorded at 17, 18, 19, and $20 \mathrm{ft}(5.2,5.5,5.8$, and $6.1 \mathrm{~m})$ using a rented control truck moving at a constant speed of $65 \mathrm{mph}(29 \mathrm{~m} / \mathrm{s})$ for each test. As a truck passed under the sign, it produced a positive pressure pulse followed by a negative pressure as the end of the truck passed. The maximum positive and negative pressure magnitudes were in the range of 1 to 2 psf (47.9-95.8 $\mathrm{Pa})$, with a mean pressure magnitude of one $\operatorname{psf}(47.9 \mathrm{~Pa})$. It was found that for every foot increase in elevation from $17 \mathrm{ft}$ ( $5.2 \mathrm{~m}$ ) above the road surface, the design pressure pulse could be decreased by $10 \%$. Finally, the significant frequencies of truck-induced gust pressure pulses were observed to range from 0.5 to $2 \mathrm{~Hz}$. These frequencies are close to the natural frequencies of VMS structures and could lead to resonance. In another study by the same authors [9], design pressures were proposed based on the previously reported tests. These values are also listed in Table 1.

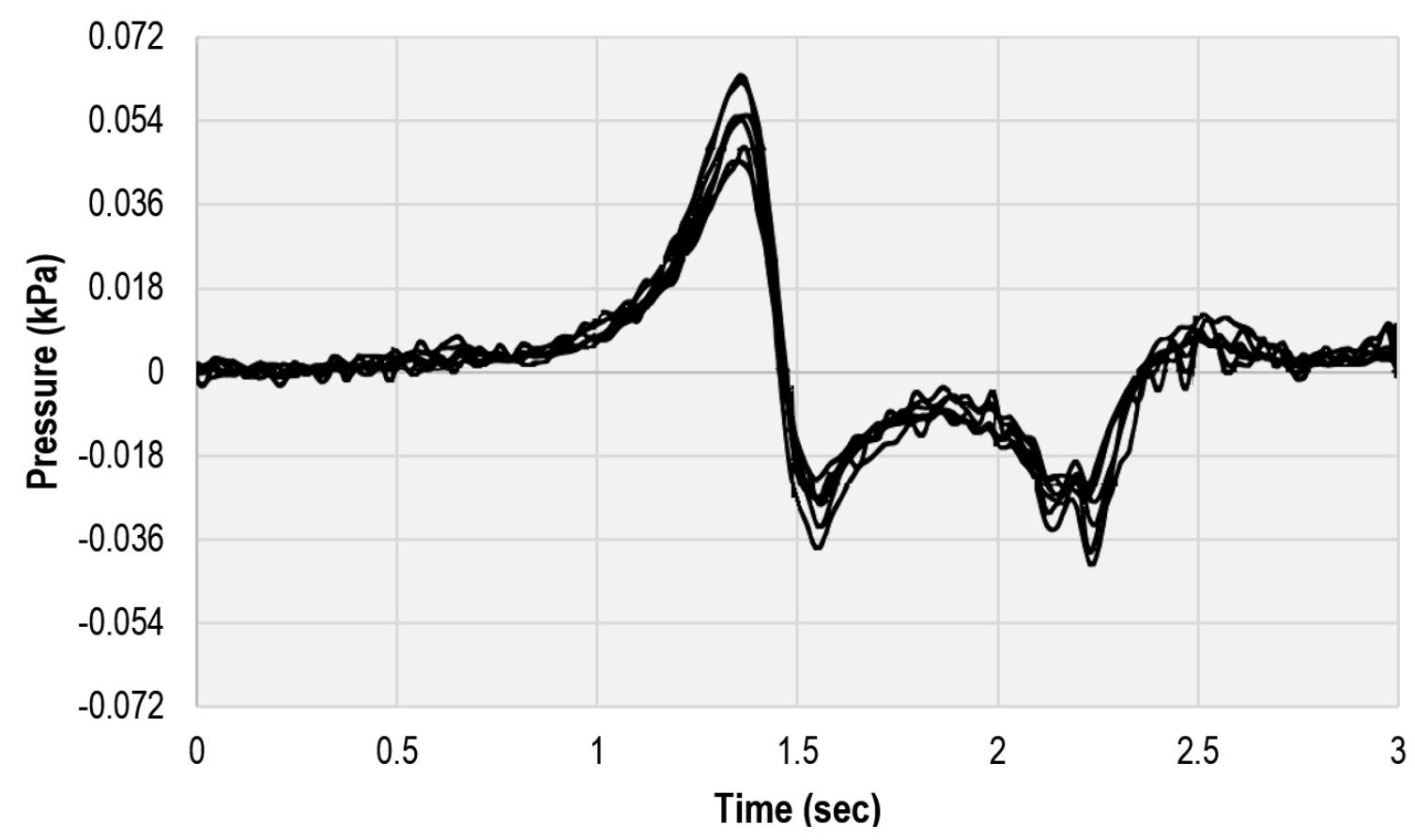

Figure 1-2: Typical truck induced gust pressure history by [8] 
Table 1: Design pressure values proposed by [9]

\begin{tabular}{|l|c|c|}
\hline & bottom horizontal surface & leading vertical surface \\
\hline positive pressure (psf) & 0.92 & 1.43 \\
\hline negative pressure (psf) & -1.50 & -2.10 \\
\hline
\end{tabular}

DeSantis and Haig presented in 1996 a simple model for the truck-gust load that incorrectly assumed the velocity of wind gusts in the upward direction is equal to the truck velocity causing quite substantial loading on the sign for trucks with over-cab air deflectors [10]. The assumption was made based on a misunderstanding of the purpose of the deflectors mounted on modern truck cabins not to deflect the air 90 degrees upward, but to make the truck more streamlined and therefore reduce the upward component of velocity in the wake forming over the cab and top of the trailer to reduce drag. The researchers used ANSYS software to reconstruct the failure conditions on a VMS structure in Virginia. The observed amplitude of vibrations of that sign in the field was about $1 \mathrm{ft}$, and assuming this deflection, the force causing it was back calculated. This force with an assumed gust factor matched the force that would be exerted by "perfectly deflected" upward air flowing at $65 \mathrm{mph}$ from a truck moving at $65 \mathrm{mph}$. On that basis the researchers concluded that the hypothesis of deflected air from trucks causing observed sign vibrations was correct. Although the value of the pressure calculated by the formulas proposed by DeSantis in [10], equal to $18.28 \mathrm{psf}$ ( $875 \mathrm{~Pa}$ ), and doubled for complete loading cycle, may be good for design purposes as very conservative, their underlying justification is wrong. These values are significantly higher than the pressures found in the numerous field studies and the current CFD analysis.

NCHRP Report 412 [11] presents results of field tests that resulted in stress ranges below those which would cause fatigue damage. The researchers concluded that the method proposed in [6] does not produce accurate results. In the next model, it was assumed that the velocity of the upward gust from a truck is equal to the velocity of the truck following DeSantis' incorrect assumption. The authors added a gust factor of 1.3 to the formula and then doubled the obtained pressure to represent the fact that during one cycle, the cantilevered arm will move both downward and upward. They found a value of $1760 \mathrm{~Pa}(36.6 \mathrm{psf})$ to be appropriate to use as an equivalent vertical static pressure. Subsequently, the DeSantis' model was recommended in NCHRP-412 [11] and then in AASHTO 2001 [5] specifications. It is unfortunate that NCHRP-412 repeats the incorrect assumptions regarding the purpose and effects of air deflectors over truck cabs stating that "It has been suggested that the wind deflectors, which are now commonly placed on the cab of tractor-trailers to improve fuel economy, act as a wedge and produce vertical wind gust pressures larger than those estimated in previous research". The proposed values are used as a basis for design procedures. This comes from a misunderstanding of the simple idea of using airfoils to increase the fuel efficiency of trucks by reducing drag. In fact the deflectors do not deflect the air, but rather keep the flow streamlines as close to the truck as possible minimizing the size of the wake. The net effect is to reduce the vertical components of wind velocity over and behind the truck cab. Introduced later NCHRP-469 [12] reduces reliance on that assumption of high upward flow velocity caused by the "deflection". It stated that fewer problems have been reported with VMS over the years between the releases of the two NCHRP documents, although 
these new structures were not designed using excessively conservative NCHRP-412 procedures. It also noted that the original design pressure value was based on limited data. Another set of field tests were performed, which confirmed that the truck induced gusts were significantly smaller than the ones assumed in previous NCHRP-412 report. In addition, it was pointed out that a wrong drag coefficient was assumed in that document for the sign, which should be 1.7. As a consequence, the magnitude of the design equivalent static pressure equation was reduced to 900. $\mathrm{C}_{\mathrm{d}} \mathrm{Pa}$ (or $18.8 \cdot \mathrm{C}_{\mathrm{d}} \mathrm{psf}$ ), where $\mathrm{C}_{\mathrm{d}}$ is the drag coefficient of the sign.

\section{CFD Model Description}

The CFD analysis focused mostly on establishing pressure histories on a variable message sign due to trucks passing under it. The geometry of the sign was built based on the CAD drawings of a scaled sign used for laboratory testing at the Turner-Fairbank Highway Research Center. The geometry of the truck was built based on the Mack CH 613 tractor with $53 \mathrm{ft}$ long trailer. The CFD analyses were conducted using unsteady implicit Reynolds Averaged Navier Stokes (RANS) flow equations for the simulations with a time step of $0.025 \mathrm{sec}$. A sliding mesh technique was used to move a subdomain containing the truck through the air domain. In this technique, common interfaces between adjacent moving subdomains are rebuilt at each time step and the fluid can pass through them without being influenced by the relative motion of the subdomains. The boundaries of the domains were placed far enough away from the truck and sign boundaries to make their influence on the pressure readings on the sign insignificant. The final model consisted of approximately 3.8 million cells with the majority concentrated around the truck and the sign. The CFD model geometry with the truck and VMS sign is shown in Figure 2-1. Initially the location of the lanes under the sign was unknown, so the trucks were located exactly under the center of the sign box as shown in Figure 2-2. Once the data on sign position with respect to the road became available the trucks were positioned within the lane locations.

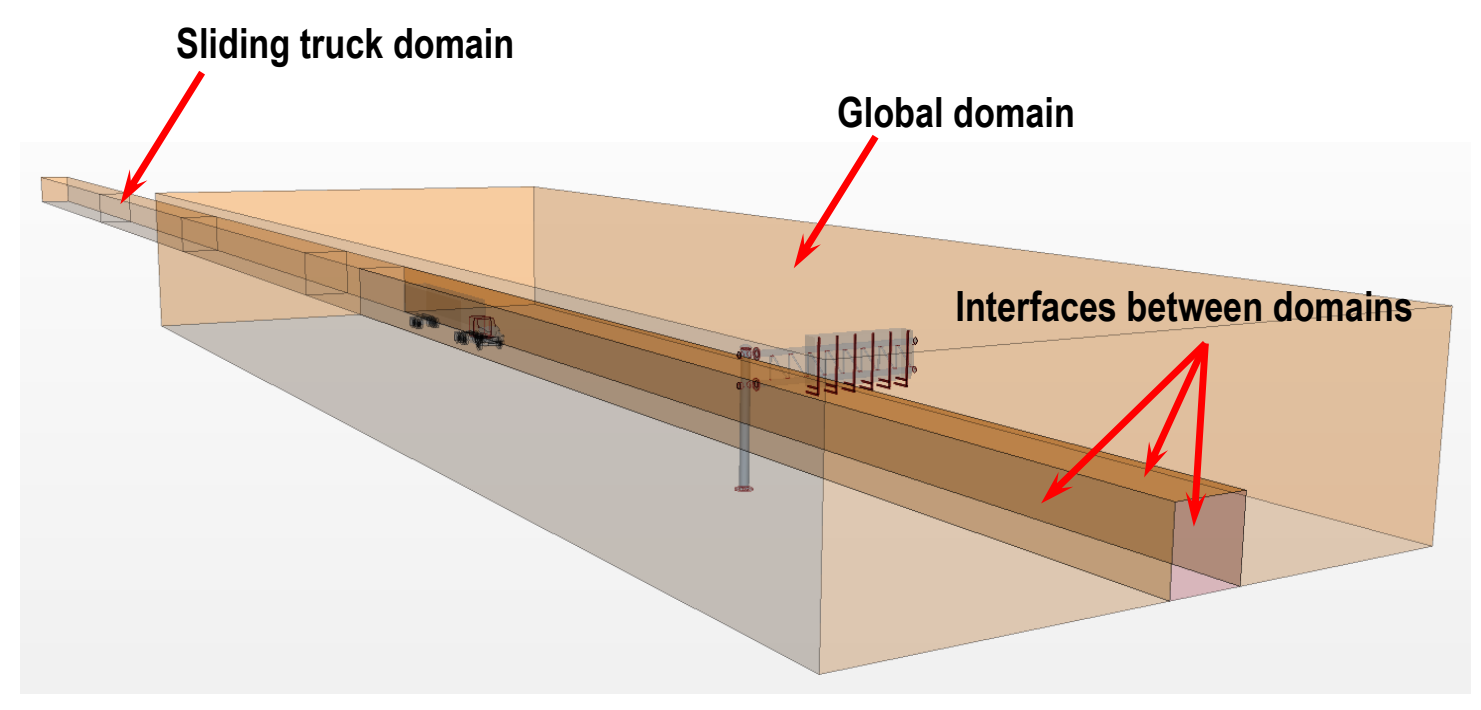

Figure 2-1: CFD model geometry with interfaces used in sliding mesh motion 


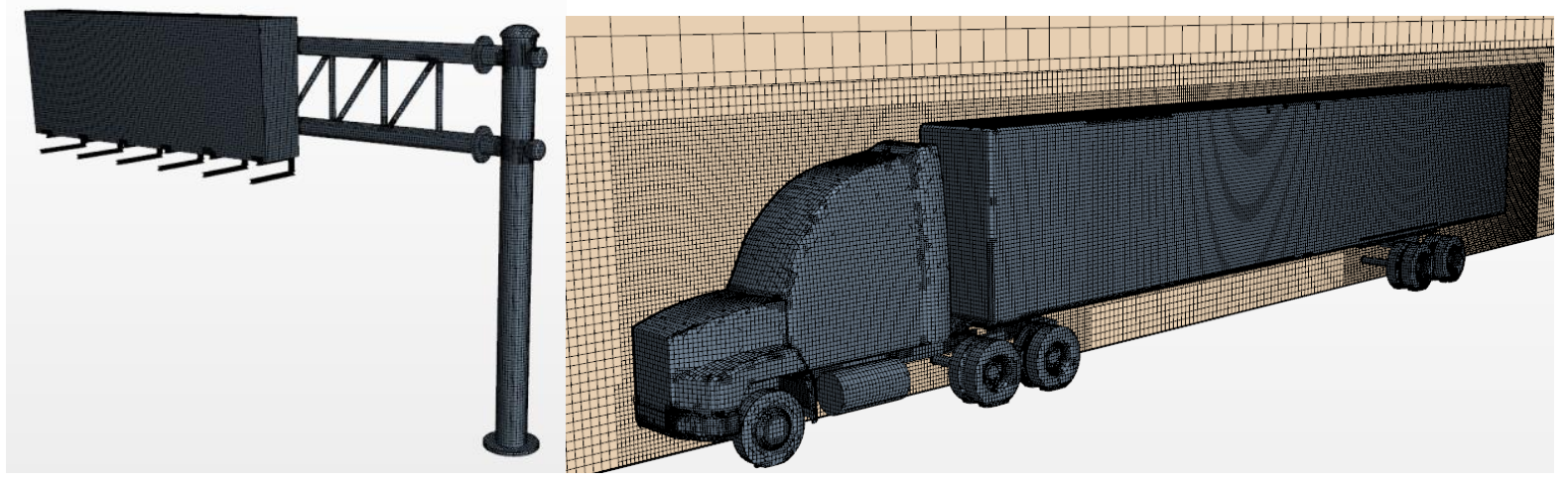

Figure 2-2: VMS and truck models

\section{Validation}

Validation of the modelling technique was performed through a comparison of numerical results with experimental data available from an experiment with a similar setup to the configuration of interest. The experimental results were obtained from data reported in [13]. The set of experiments described in [13] pertained to six different types of vehicles and three different sizes of square plates (of $0.5,1.0$ and $1.5 \mathrm{~m}$ edge size) that were placed in three different configurations in respect to the truck axis of motion: (1) above the truck, (2) on the side of the truck perpendicular to the axis of the vehicle, and (3) on the side of the truck parallel to the axis of the vehicle. The velocity of the truck and the distance of the plates from the vehicle were also varied in these experiments. The resultant forces exerted on the plates by the moving vehicles were registered as functions of time. All the curves for each particular vehicle type and the plate location were normalized. Using proposed distance model, and scaling factors for vehicle's velocity and frontal area, a distinct curve for a specific case can be obtained from the website maintained by the researchers.

Out of all the documented data, a portion of the results for trailer truck with the largest plate (1.5 $\mathrm{m}$ by $1.5 \mathrm{~m}$ ) located above the vehicle was used for the validation as the closest to the investigated VMS cases. The European type trucks have a boxy shape of the cabin with flat frontal surface (see Figure 3-1). A representative geometry and CFD model of the European type truck was built for the purpose of the validation effort. Two distances of the plate above the truck $(1.1 \mathrm{~m}$ and $1.37 \mathrm{~m})$ as well as two velocities of the truck (50 mph and $60 \mathrm{mph}$ ) focused on. Figure 3-2 shows a profile of the air velocity magnitude around the truck when the truck box is set in motion and sliding relatively to the stationary domain above and around it. The interface between the moving box with the truck and the stationary domain is not disturbing that profile. The sliding mesh model was not causing any numerical issues. 


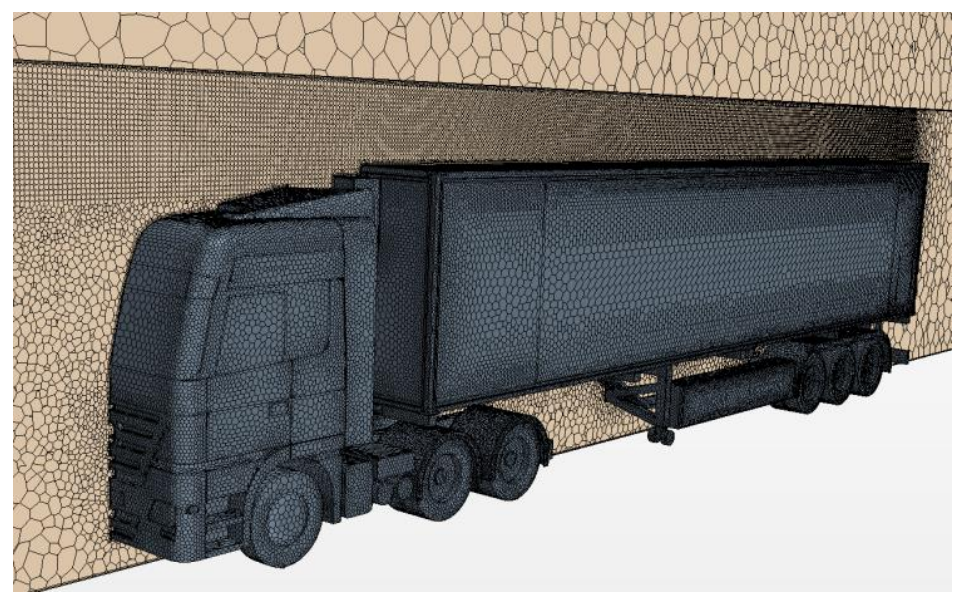

Figure 3-1: A model of European type trucks with a flat and boxy shape of the cabin

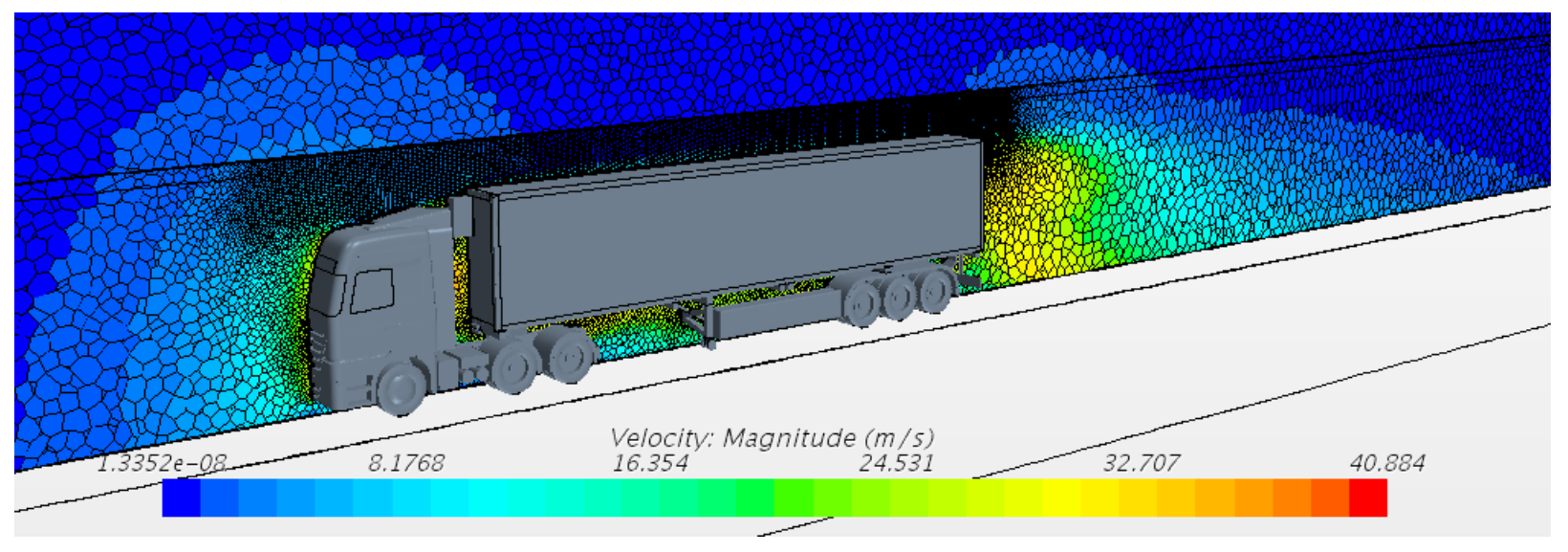

Figure 3-2: Profile of the air velocities around the truck when the truck box is set in motion

Figure 3-3 through Figure 3-6 show a comparison between force histories obtained experimentally and numerically. Figure 3-3 and Figure 3-4 show the forces for the plate located $1.1 \mathrm{~m}$ above the truck, while Figure 3-5 and Figure 3-6 show the force histories for plates located $1.37 \mathrm{~m}$ above the truck. The shape of the numerically predicted force histories matches quite well the experimentally obtained curves. The peak values of the forces predicted numerically was also in good agreement with the experimental data. For the trucks traveling at $50 \mathrm{mph}$ the simulations were under predicting the maximum force by about $10 \%$. For the trucks traveling at $60 \mathrm{mph}$ the numerically predicted peak forces were about $10 \%$ larger than the experimental values. 


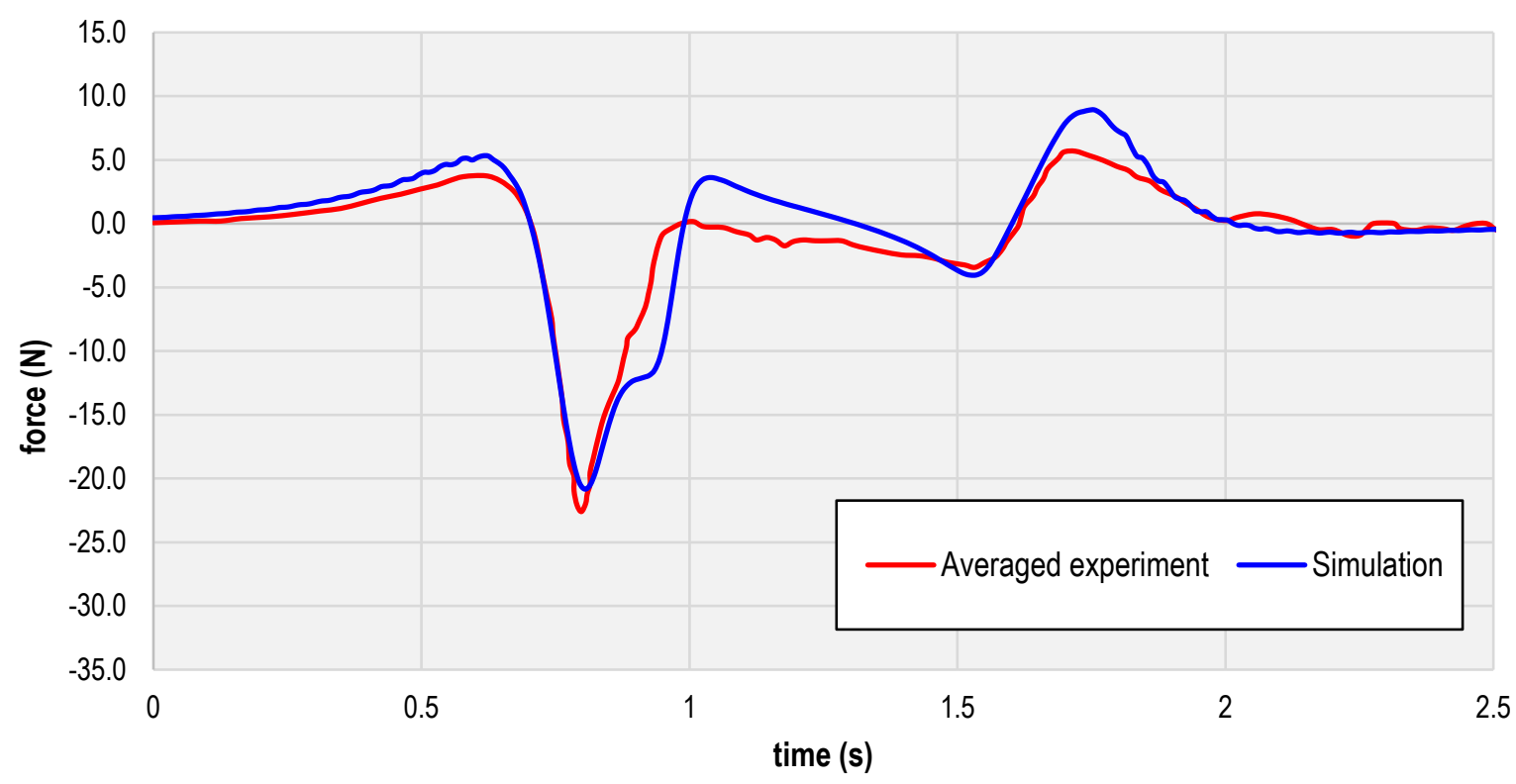

Figure 3-3: Time history of the force acting a plate located $1.1 \mathrm{~m}$ above the truck which is travelling at $50 \mathrm{mph}$

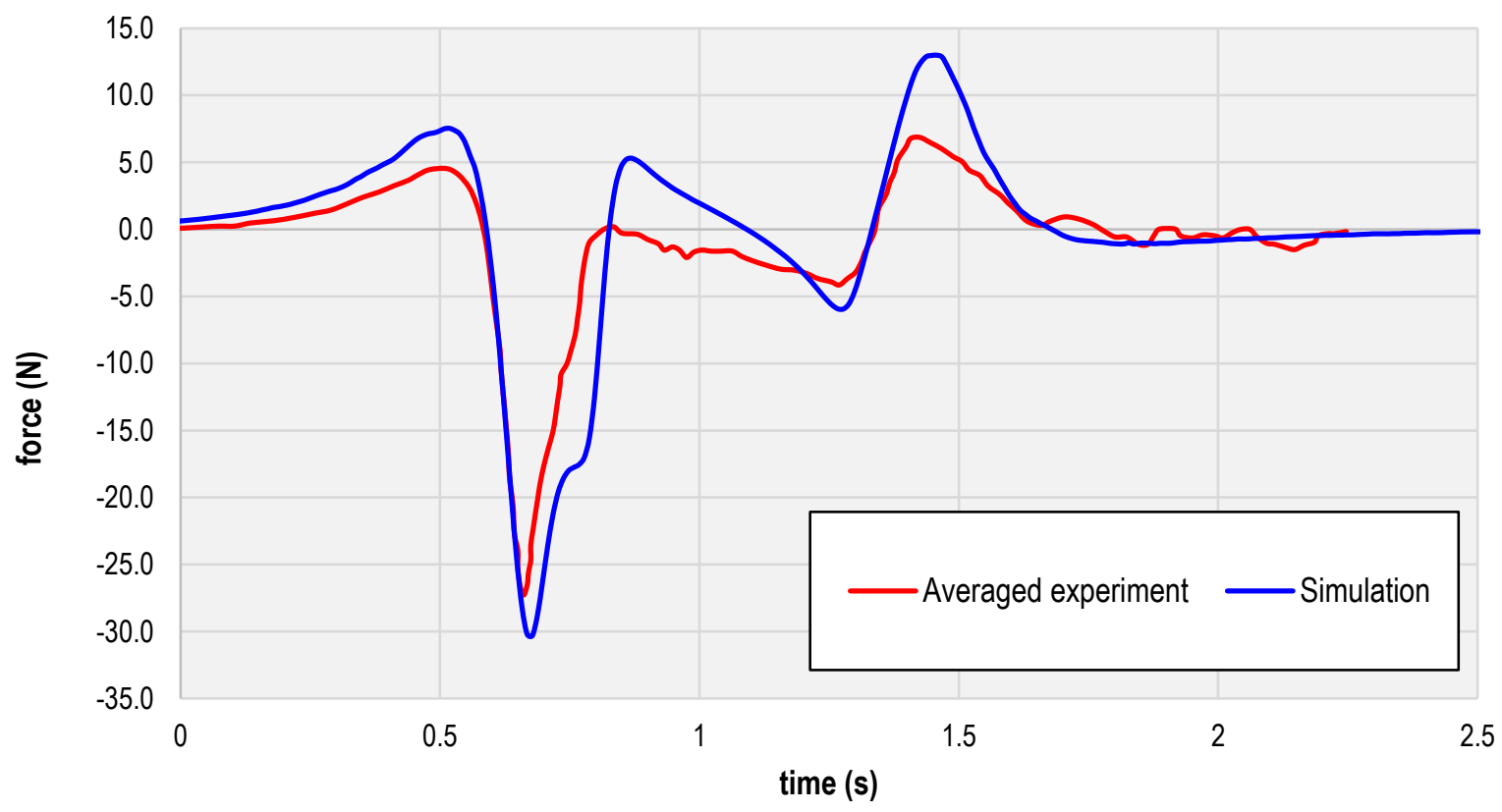

Figure 3-4: Time history of the force acting a plate located $1.1 \mathrm{~m}$ above the truck which is travelling at $60 \mathrm{mph}$ 


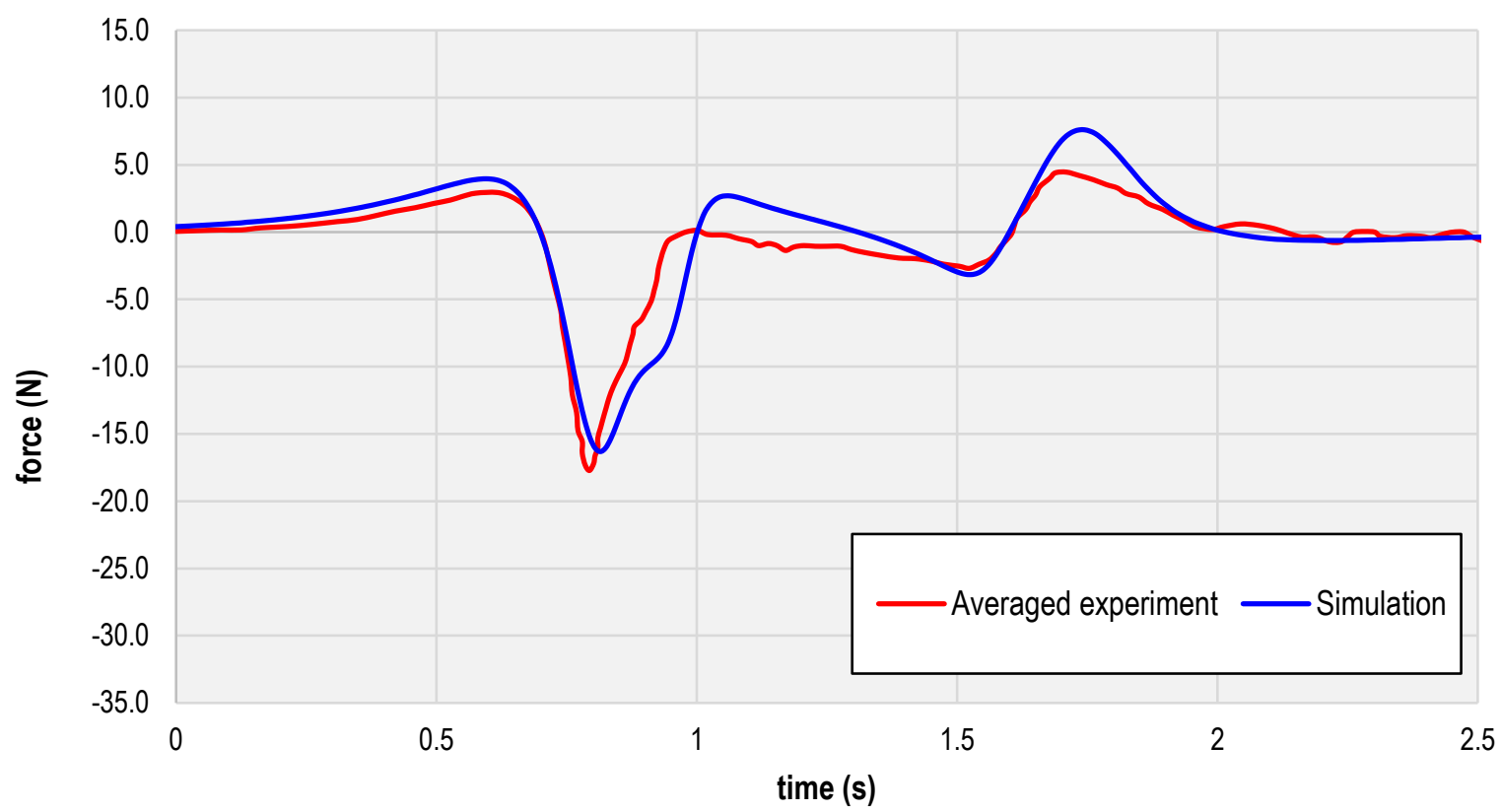

Figure 3-5: Time history of the force acting a plate located $1.37 \mathrm{~m}$ above the truck which is travelling at $50 \mathrm{mph}$

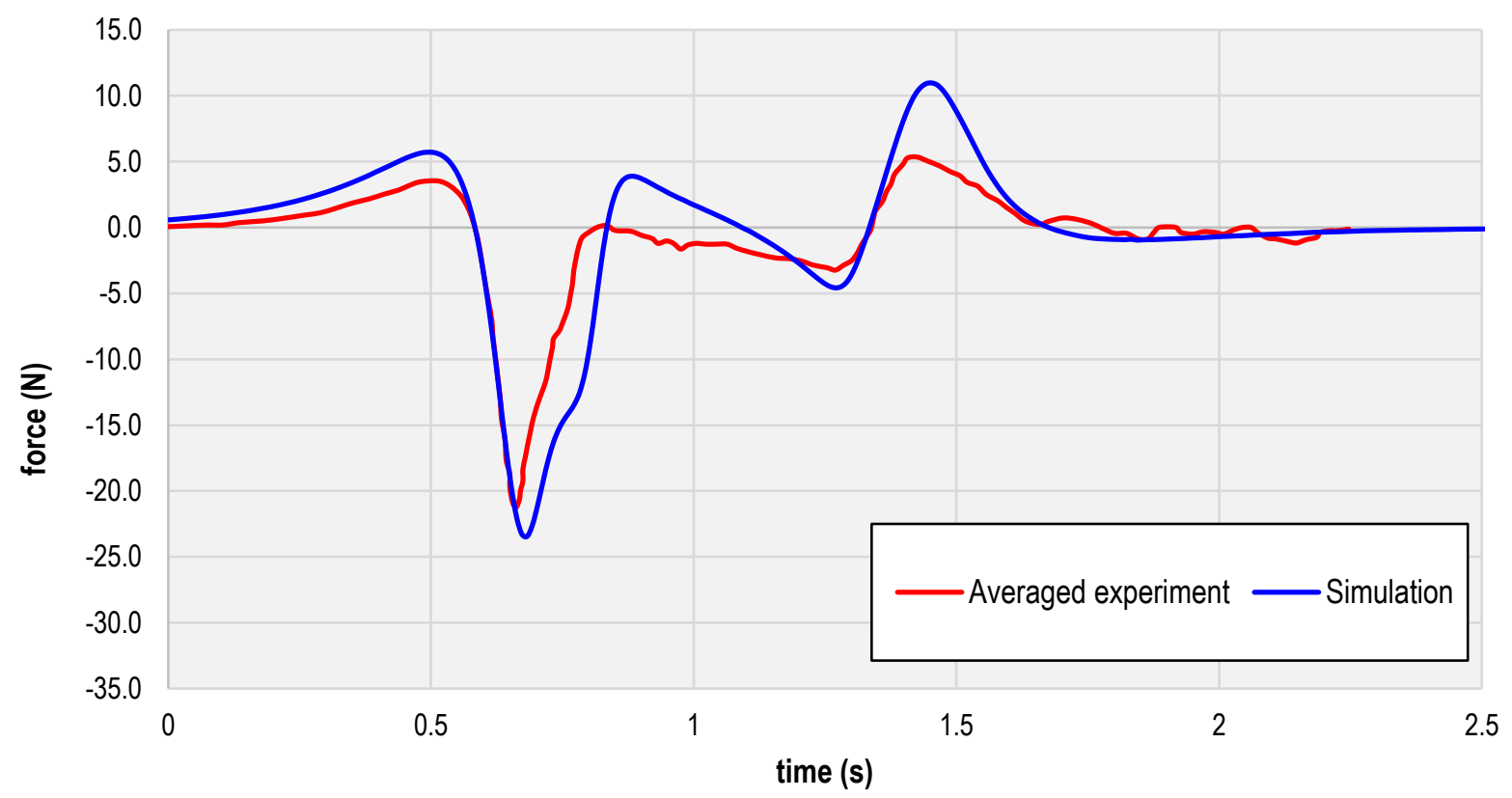

Figure 3-6: Time history of the force acting a plate located $1.37 \mathrm{~m}$ above the truck which is travelling at $60 \mathrm{mph}$ 


\section{Parametric Study}

Once the validity of the CFD models was assured, an influence of several parameters on the forces acting on the VMS was investigated. The following parameters and their ranges were taken into account:

- $\quad$ Truck velocity (from $40 \mathrm{mph}$ to $70 \mathrm{mph}$ with $10 \mathrm{mph}$ increments),

- Nominal clearance between the sign bottom panel and the road surface (from $18 \mathrm{ft}$ to 20 $\mathrm{ft}$ with $1 \mathrm{ft}$ increments), and

- Truck cabin type (non-streamlined without flow diverter and a streamlined, or smooth, truck with a flow diverter above the cabin, see Figure 4-1 for explanation)

The full test matrix is presented in Table 2.

Table 2: Analyzed cases in the CFD analysis

\begin{tabular}{|c|c|c|c|c|}
\hline $\begin{array}{c}\text { Truck } \\
\text { Velocity }\end{array}$ & $\begin{array}{l}\text { Sign height } \\
\text { above the } \\
\text { ground - } \\
\text { change to } \\
\text { clearance }\end{array}$ & Truck shape & $\begin{array}{l}\text { Wind } \\
\text { action }\end{array}$ & Truck location \\
\hline $40 \mathrm{mph}$ & $19 \mathrm{ft}$ & $\begin{array}{c}\text { streamlined, } \\
\text { non-streamlined }\end{array}$ & none & center \\
\hline 50 mph & $19 \mathrm{ft}$ & $\begin{array}{c}\text { streamlined, } \\
\text { non-streamlined }\end{array}$ & none & center \\
\hline $60 \mathrm{mph}$ & $19 \mathrm{ft}$ & $\begin{array}{c}\text { streamlined, } \\
\text { non-streamlined }\end{array}$ & none & center \\
\hline $70 \mathrm{mph}$ & $18 \mathrm{ft}, 19 \mathrm{ft}, 20 \mathrm{ft}$ & $\begin{array}{c}\text { streamlined, } \\
\text { non-streamlined }\end{array}$ & $\begin{array}{c}10 \mathrm{mph} \\
\text { head wind }\end{array}$ & center \\
\hline $70 \mathrm{mph}$ & $19 \mathrm{ft}$ & non-streamlined & none & $\begin{array}{l}\text { left lane, center, } \\
\text { two trucks under the } \\
\text { sign }\end{array}$ \\
\hline
\end{tabular}

To compare between the cases, the pressures acting on the sign with readings from two points were analyzed (histories are available for the whole sign surface) (1) near the bottom of the front panel, (2) In the middle of the bottom panel. The selected points were located in the areas where local peak pressures were registered. 

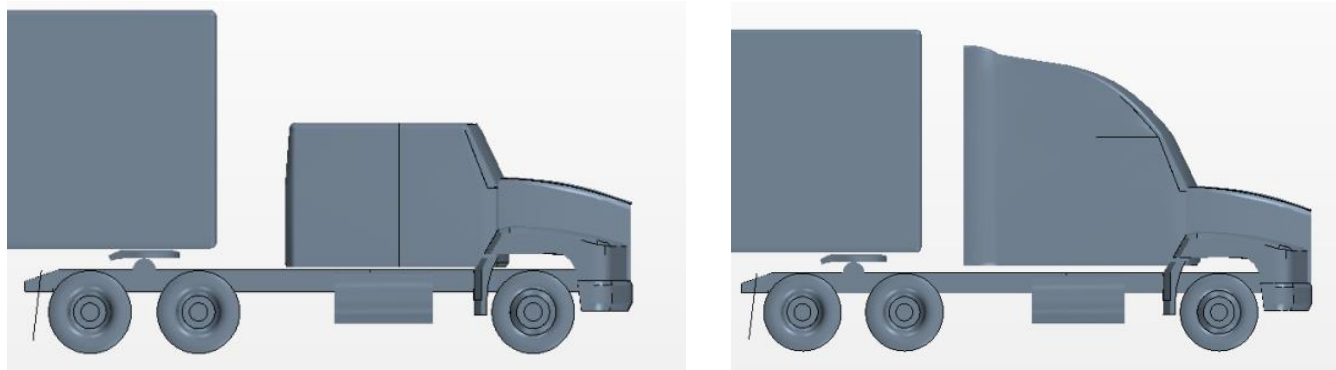

Figure 4-1: Trucks without and with over cab flow diverter or non-streamlined and streamlined

Typical pressure curves on the front panel found in the analyses with the non-streamlined truck passing under the middle of the sign are shown in Figure 4-2. The curves start with a positive phase when the truck approaches the sign. A negative phase with two local peaks starts when the tractor reaches the sign position and continues until the rear of the trailer approaches the sign. Another small positive phase ends the pressure history when the wake behind the truck passes the sign. The shape of the curve resembles the curves obtained in the experimental studies presented in [8] (also shown in Figure 1-2). However, the stretch and magnitude of the peaks will differ depending on the truck and sign shape, truck velocity, wind speed, and other minor effects.

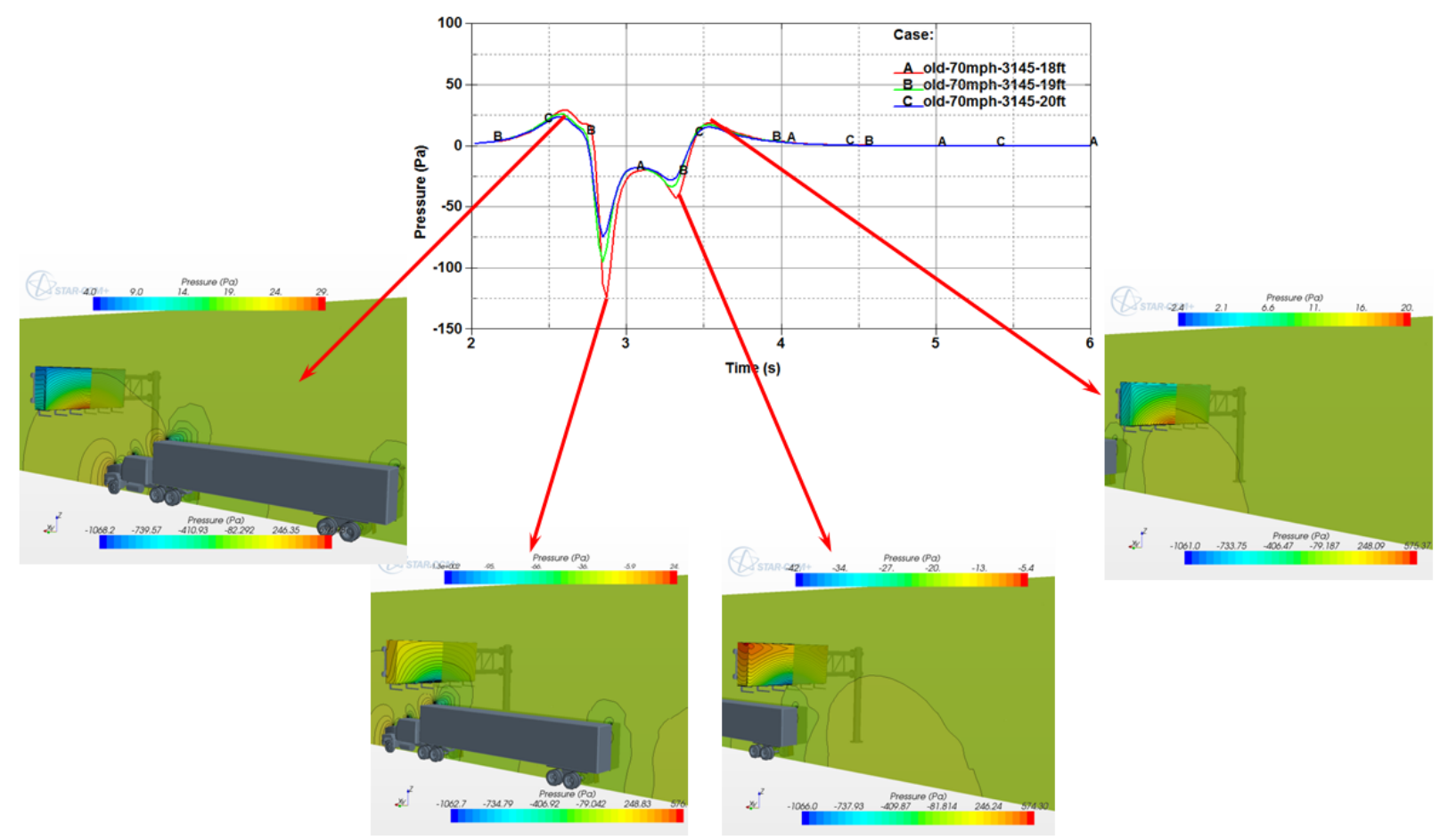

Figure 4-2: Positions of the truck corresponding to the peaks in the pressure history Close up views of the pressure distribution on the sign surface at the moments of local negative peaks are presented in Figure 4-3. Only a small patch on the sign panels is loaded with pressure 
close to the maximum pressure values. The average pressure on the panels is significantly lower. When the maximum negative pressure is near $150 \mathrm{~Pa}$, the average pressure can be as low as about $40 \mathrm{~Pa}$.

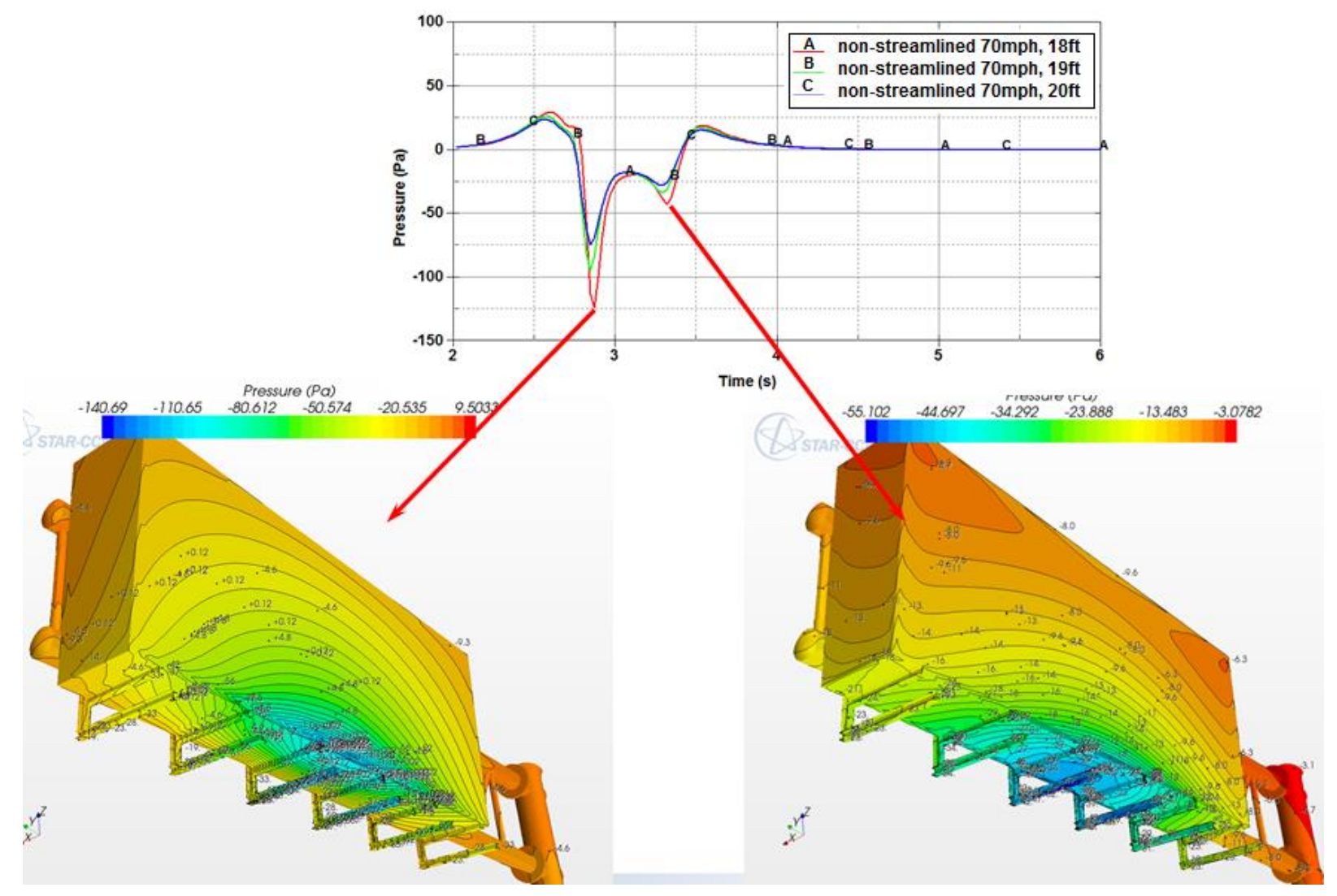

Figure 4-3: Pressure distribution on the sign surface at the time when local negative peaks occur

The truck velocity was one of the varied parameters in the simulations. It varied from $40 \mathrm{mph}$ to $70 \mathrm{mph}(17.9 \mathrm{~m} / \mathrm{s}$ to $31.3 \mathrm{~m} / \mathrm{s})$. Figure $4-4$ and Figure $4-5$ show the pressure histories on the front panel for the streamlined and non-streamlined trucks respectively. Figure 4-6 and Figure 4-7 show similar plots for the bottom panel of the sign. The length of the pressure impulse increases as the truck speed decreases. The maximum value of negative pressure $59.7 \mathrm{~Pa}$ dropped by $67 \%$ to $19.6 \mathrm{~Pa}$ on the front panel as the speed drops from 70 to $40 \mathrm{mph}$ for the streamlined truck, and it drops from 69.5 Pa to 22.3 Pa on the bottom panel. In the case of the non-streamlined truck the peak values were significantly higher. The maximum pressure on the front panel was 94.7 $\mathrm{Pa}$, which is $59 \%$ more than for the case of streamlined truck. This value dropped to $34.2 \mathrm{~Pa}$ (64 \%) when the velocity of the truck was decreased to $40 \mathrm{mph}$. The maximum pressure on the bottom panel dropped from 114.6 Pa for the truck traveling with velocity of $70 \mathrm{mph}$ to $39.7 \mathrm{~Pa}$ for the truck with speed of $40 \mathrm{mph}$. 


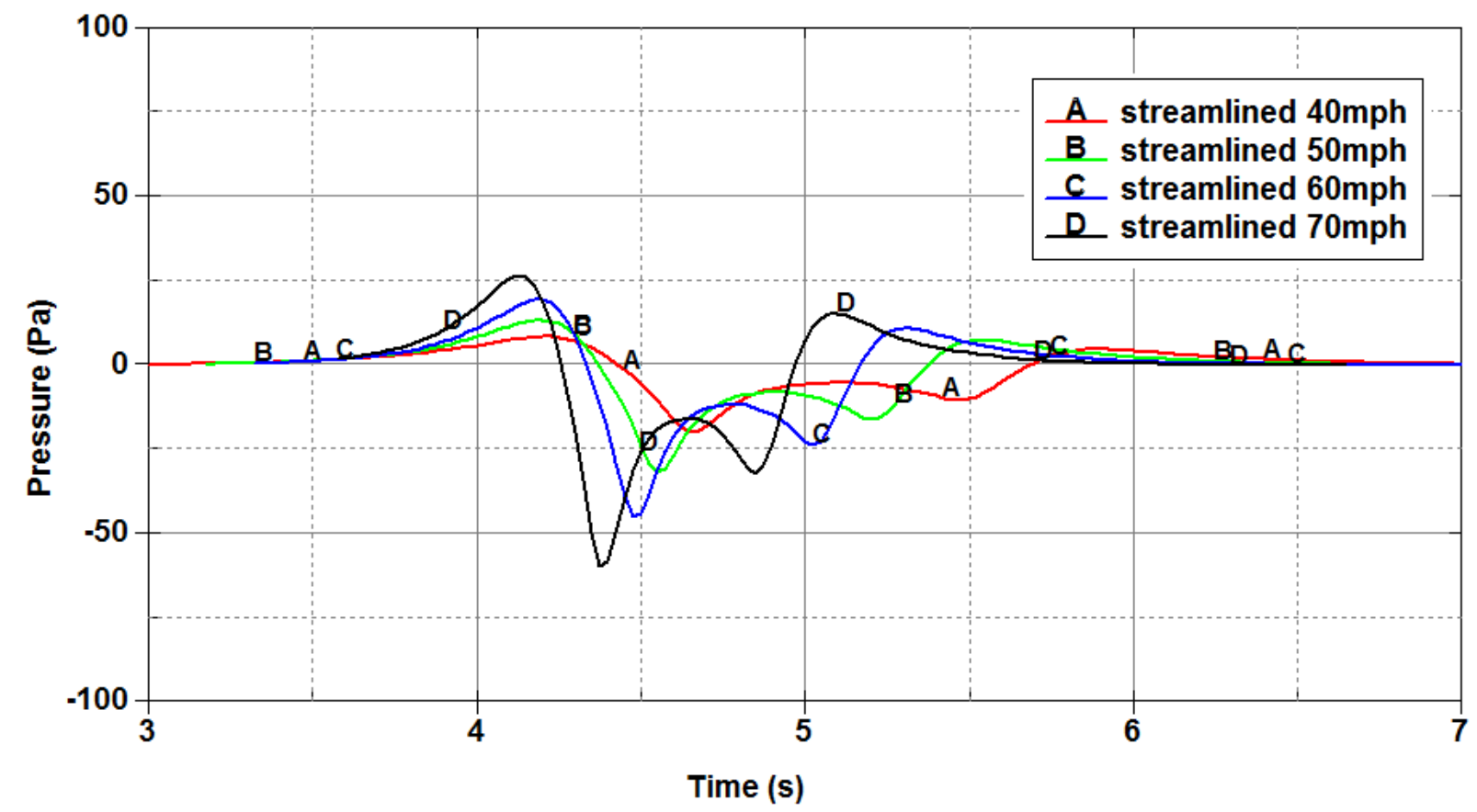

Figure 4-4: Pressure history on the front panel of the sign for simulations with streamlined truck and different velocities

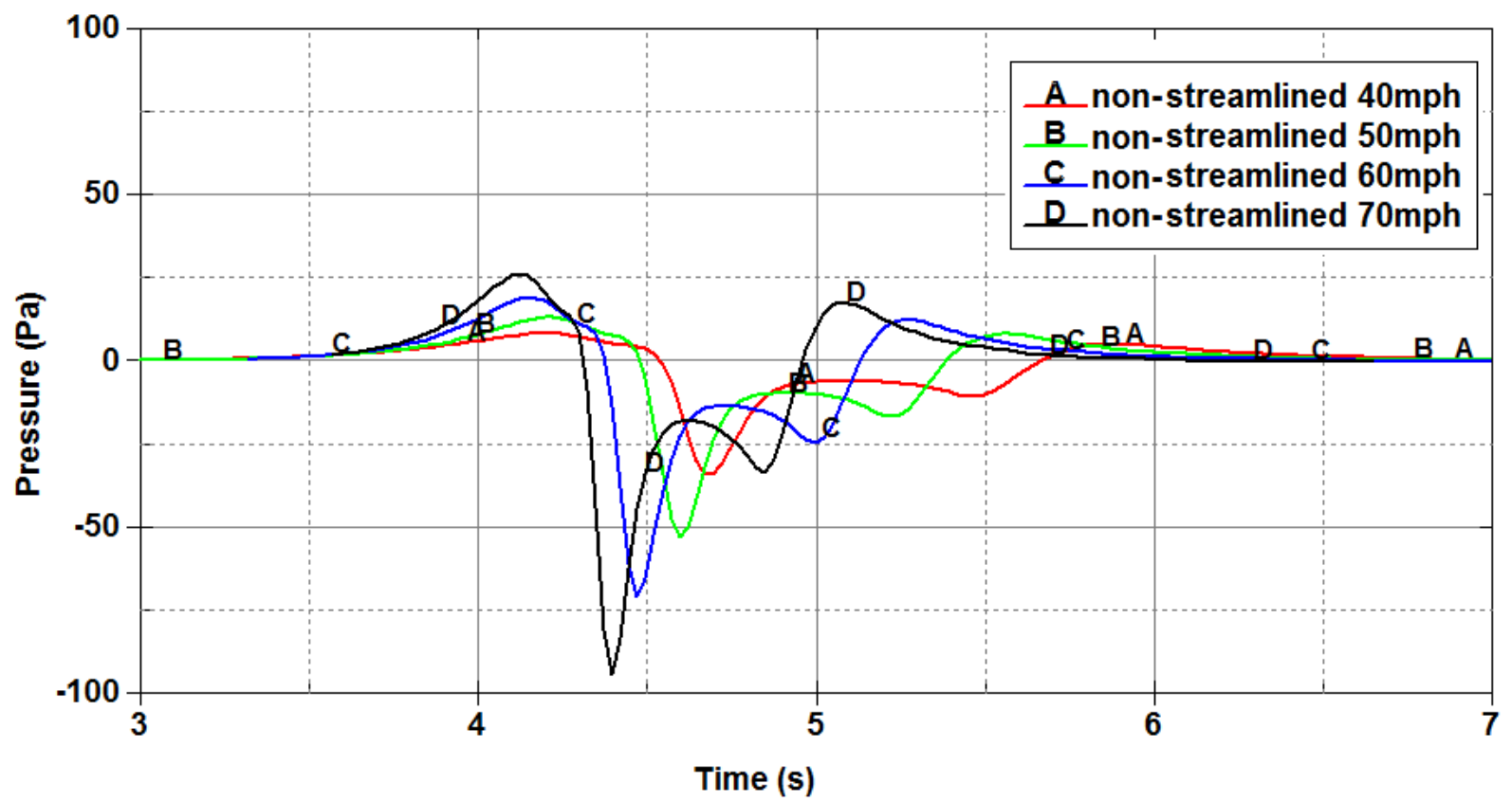

Figure 4-5: Pressure history on the front panel of the sign for simulations with non-streamlined truck and different velocities 


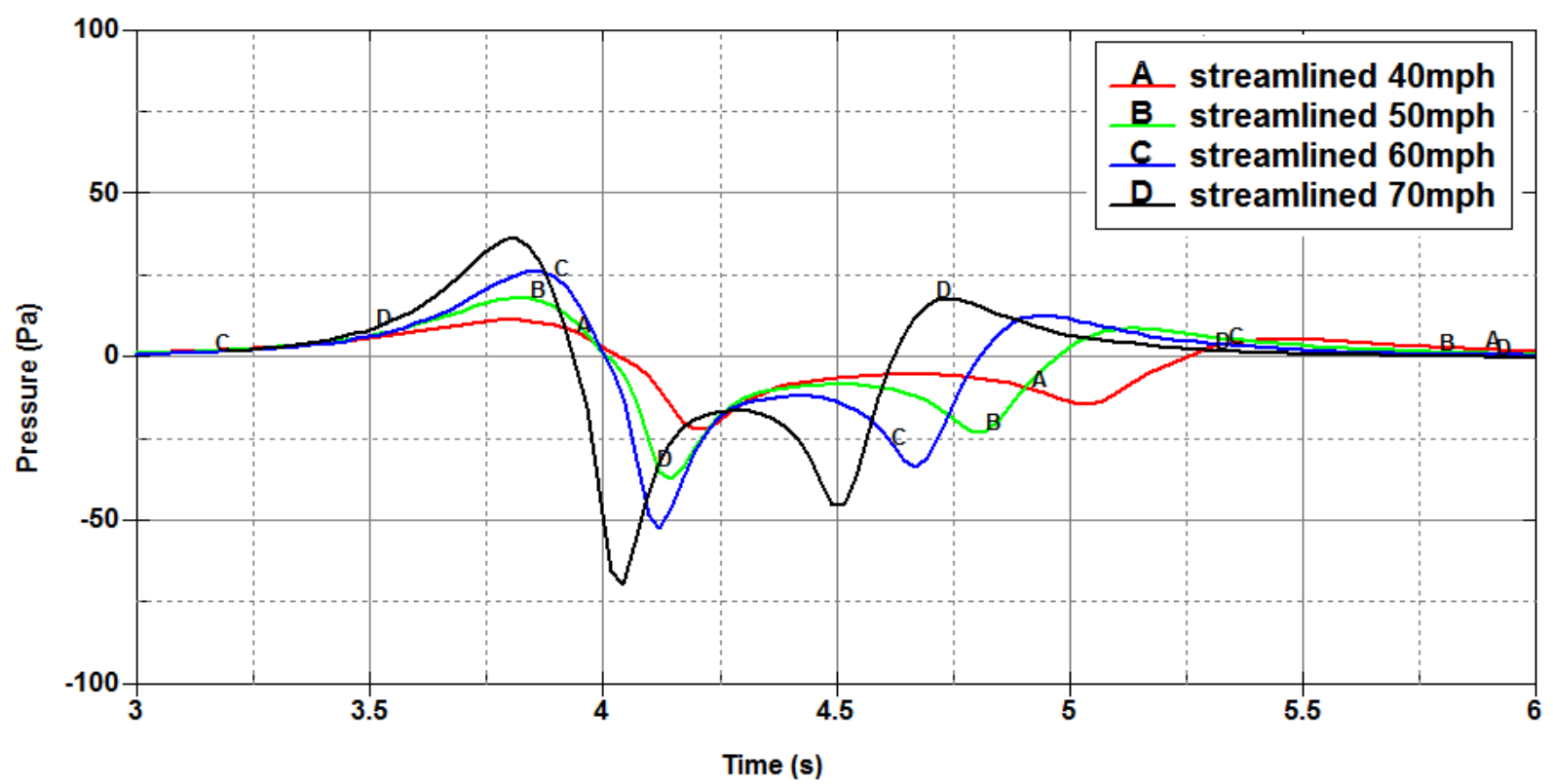

Figure 4-6: Pressure history on the bottom panel of the sign for simulations with streamlined truck and different velocities

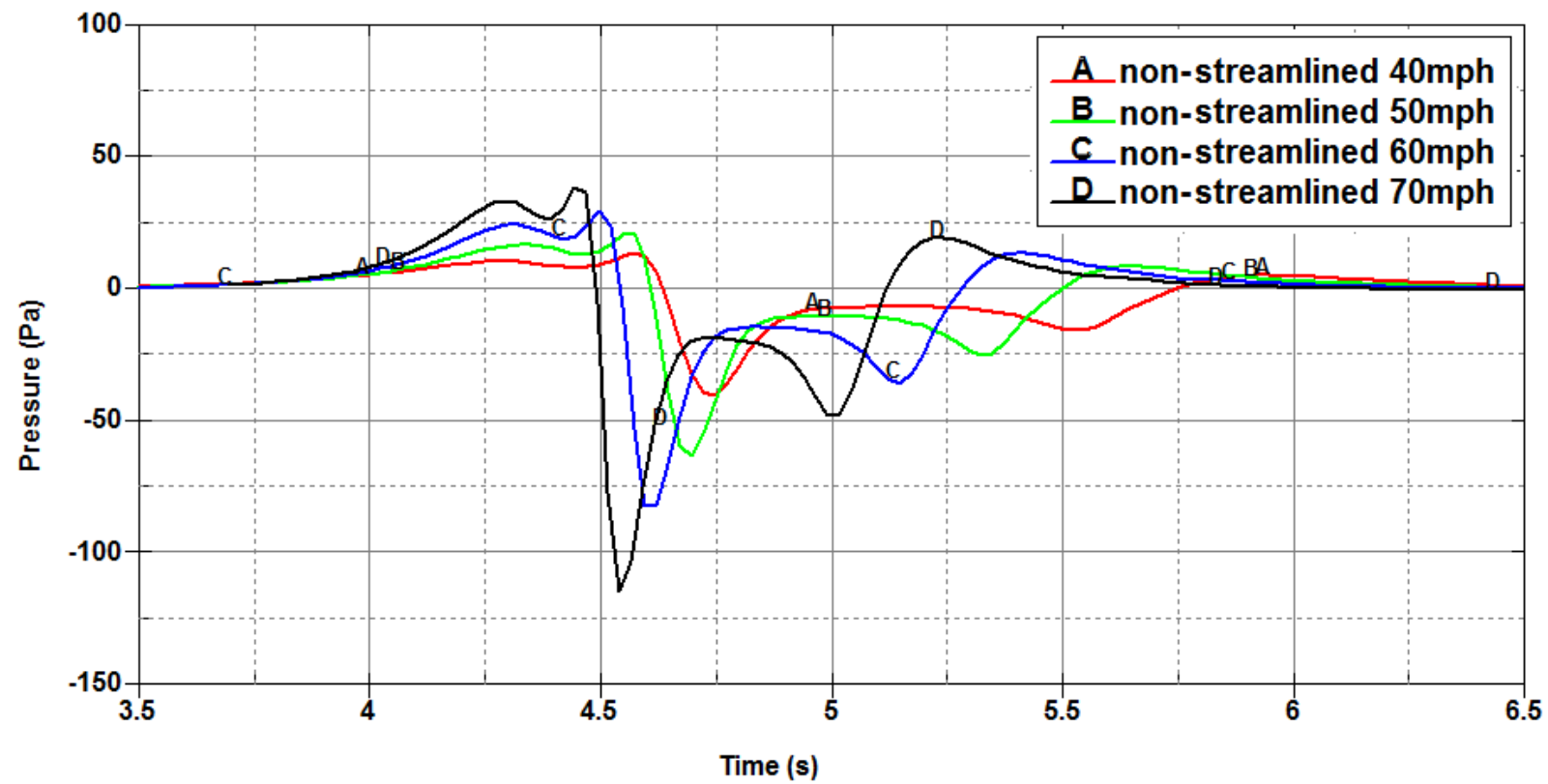

Figure 4-7: Pressure history on the bottom panel of the sign for simulations with nonstreamlined truck and different velocities 
Figure 4-8 shows trends of the maximum negative pressure for the cases summarized here. It can be concluded that the pressure increases almost linearly for the streamlined truck as its velocity increases. There is slight non-linearity in the pressure increase for the non-streamlined truck. Also the slope of the fitted linear trend is higher for the non-streamlined truck.

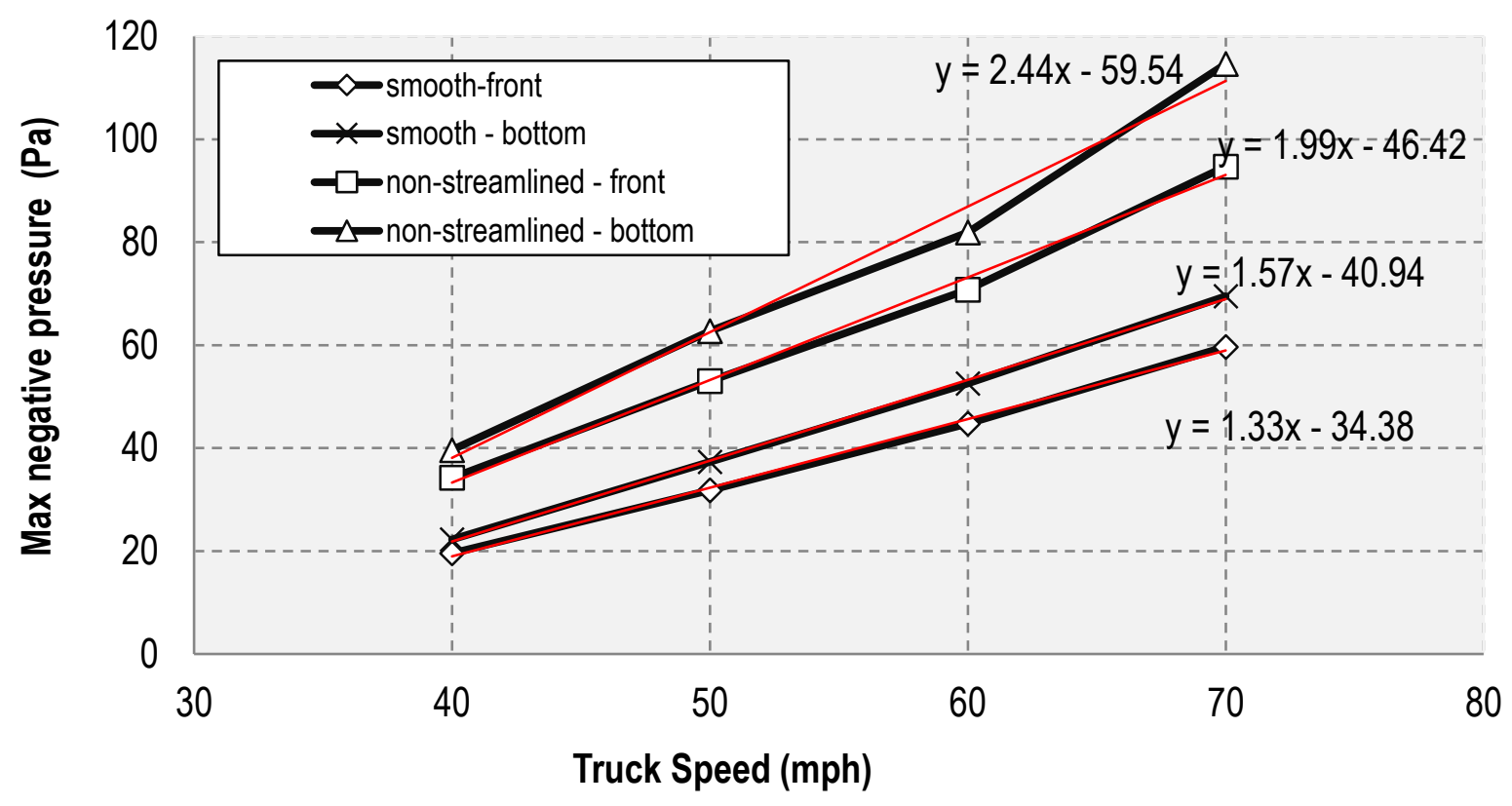

Figure 4-8: Dependency of the pressure on the truck speed

The influence of sign height variation on the pressure magnitude was studied for the nonstreamlined truck traveling with the speed of 70 mph. Figure 4-9 and Figure 4-10 show pressure histories on the front and the bottom panel in these cases.

Figure 4-11 shows a cumulative plot with maximum negative pressures read from previous plots for the non-streamlined truck and different sign heights. It would be beneficial to analyze more cases to better determine the trends, but from this limited data it appears that the pressure may nearly linearly decrease with the increasing height of the sign (or distance between the truck and the bottom of the sign box). 


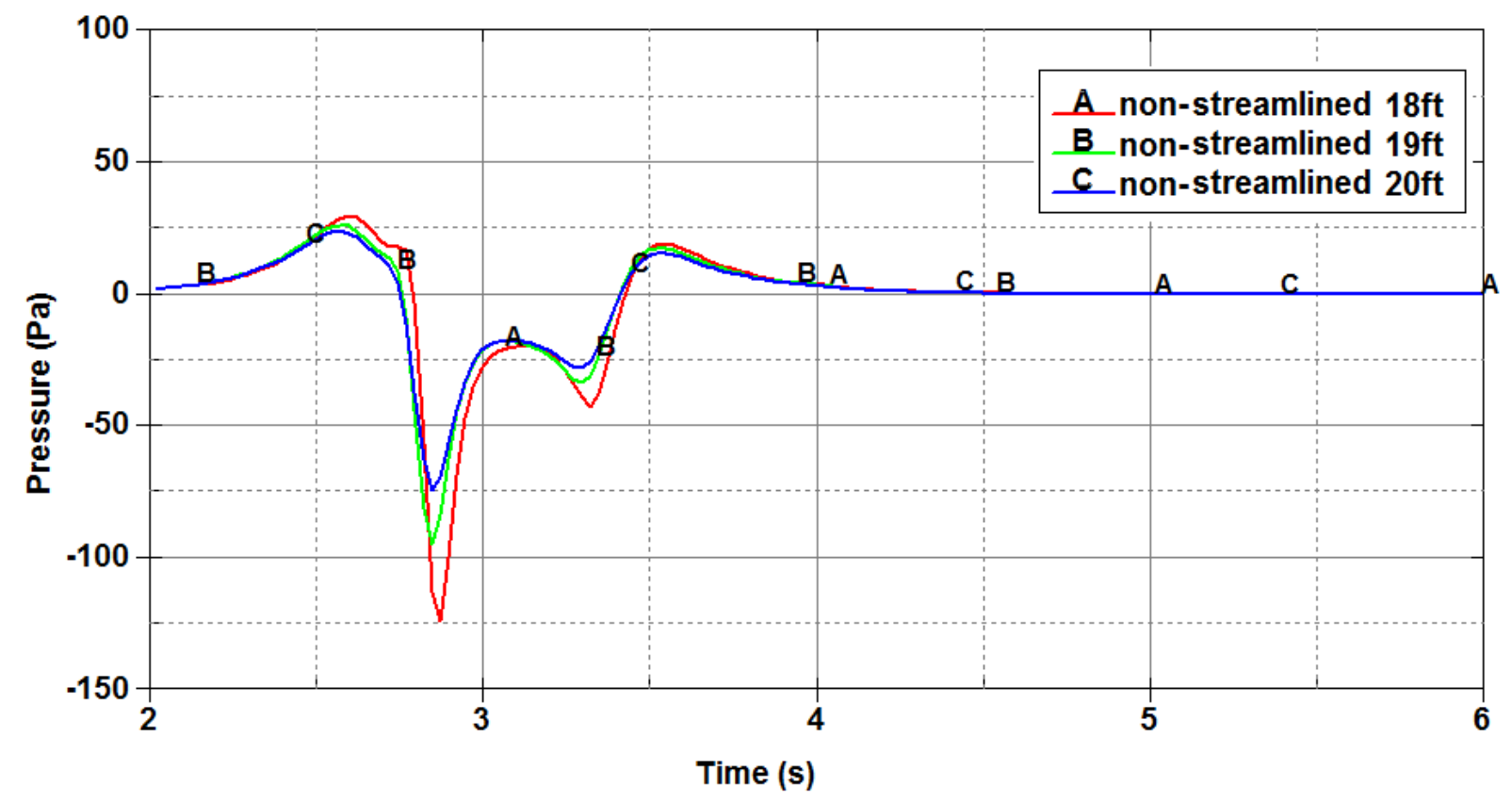

Figure 4-9: Pressure history on the front panel of the sign for simulations with non-streamlined truck and different sign height

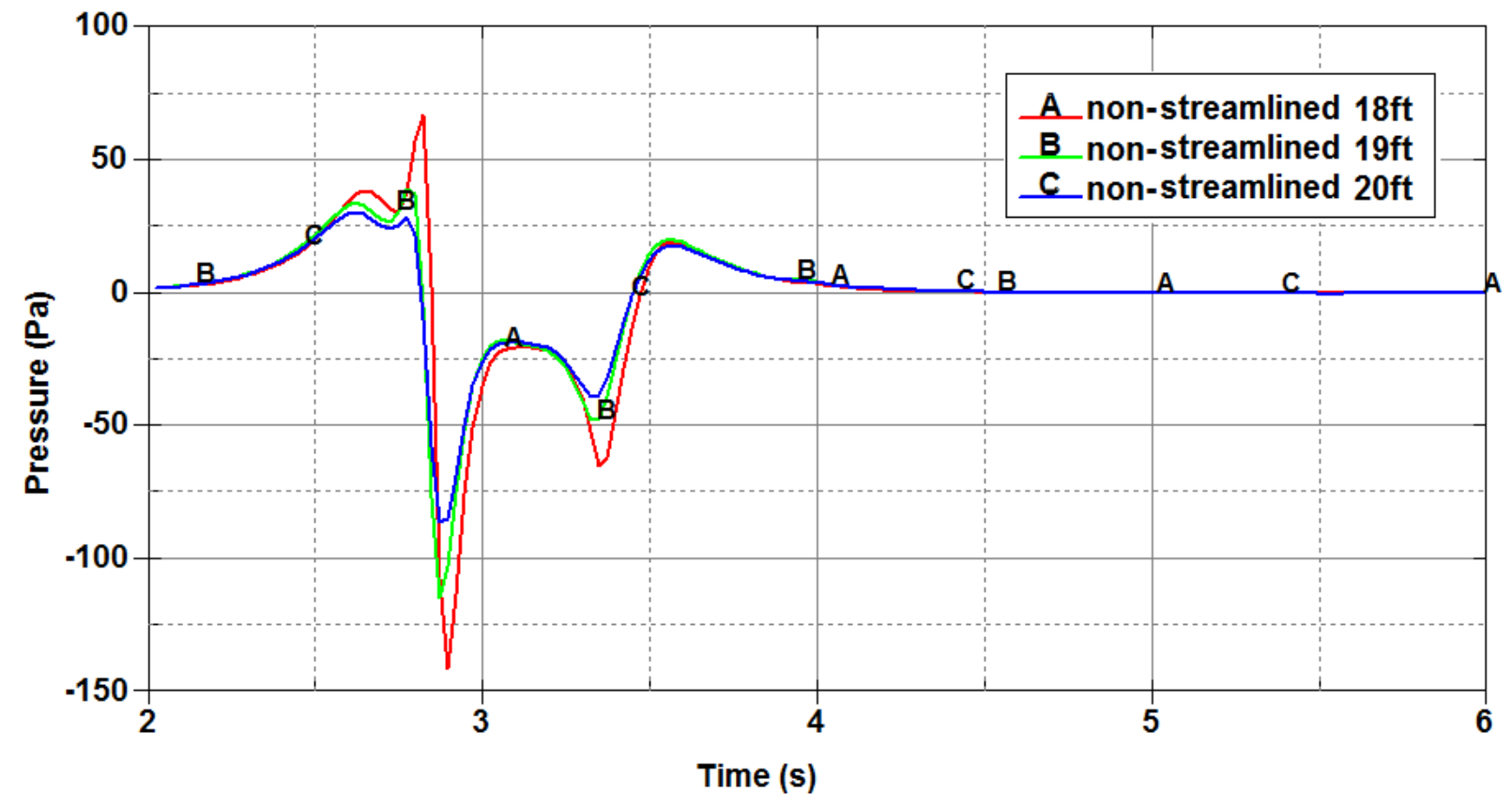

Figure 4-10: Pressure history on the bottom panel of the sign for simulations with nonstreamlined truck and different sign height 


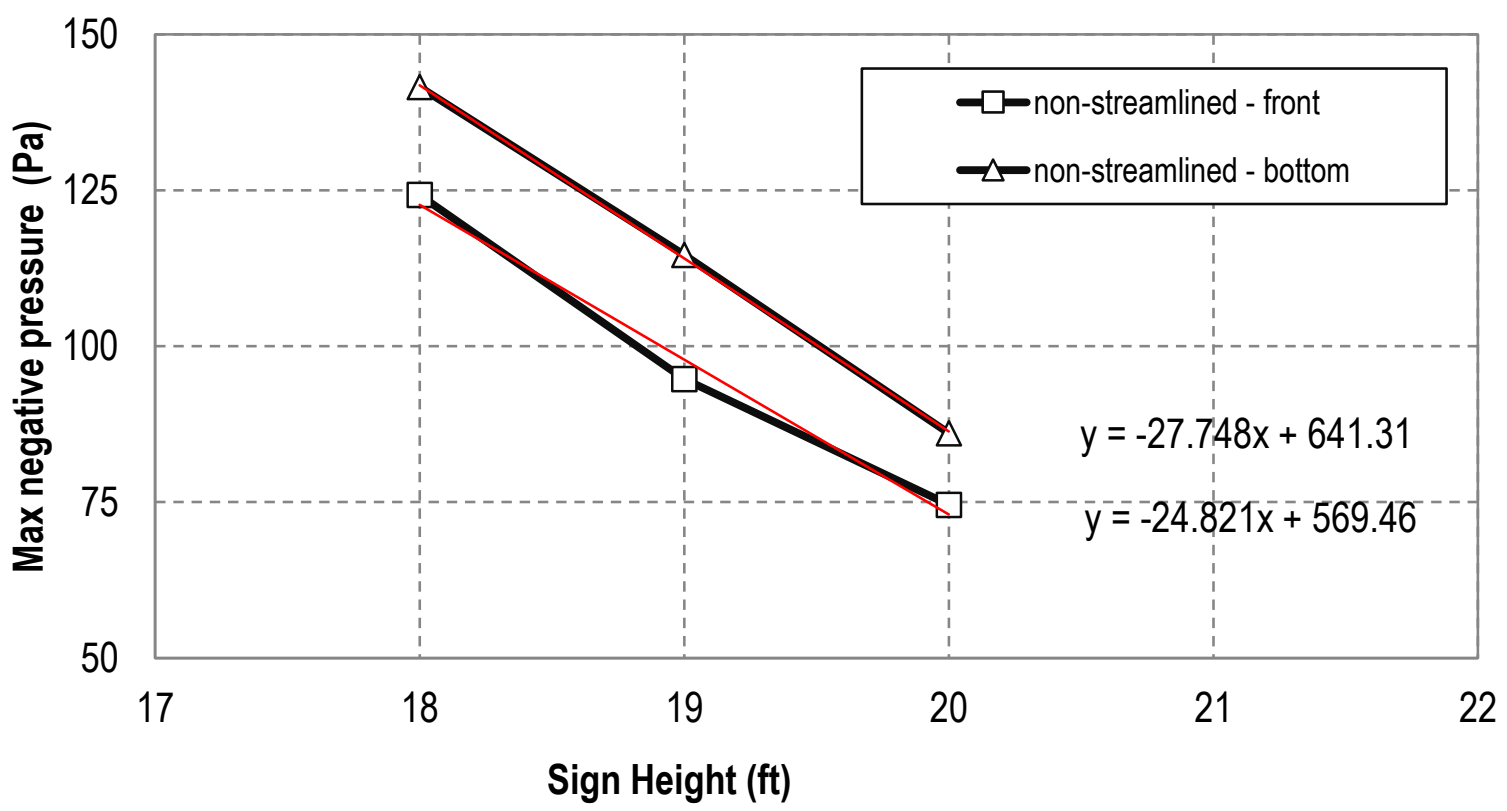

Figure 4-11: Dependency of the pressure on the sign height (add $21 \mathrm{ft}$ and the streamlined truck), change sign height to clearance

Initial simulations were performed with the truck located under the center of the sign, as the design configuration over the road was unknown. Later, when the drawings were made available, cases with the truck placed on the left travel lane (generating largest bending moment in the cantilever) and two trucks located side by side on two lanes underneath the sign were analyzed. Figure 4-12 shows a drawing of the sign and its location relative to the travel lanes. Figure 4-13 shows the model from the case with two trucks side by side.

Figure 4-14 and Figure 4-15 show pressure history on the front and bottom panel respectively for the cases with the truck moved to the left lane and also two trucks moving side by side. These curves are compared to the previously obtained pressure histories for the case with truck traveling underneath the center of the VMS box. Looking at the front panel, the maximum pressure in the middle of it dropped to 62.9 $\mathrm{Pa}$. That doesn't mean the maximum pressure reading has dropped - it has just moved to the side and the value at element 3145 has dropped. For the case with two trucks passing next to each other this value has increased to $144.2 \mathrm{~Pa}$. On the bottom panel the difference between the maximum value of pressure for one truck passing under the center of the sign and two trucks side by side wasn't significant. It has increased from 114.6 Pa to 128.7 Pa. 


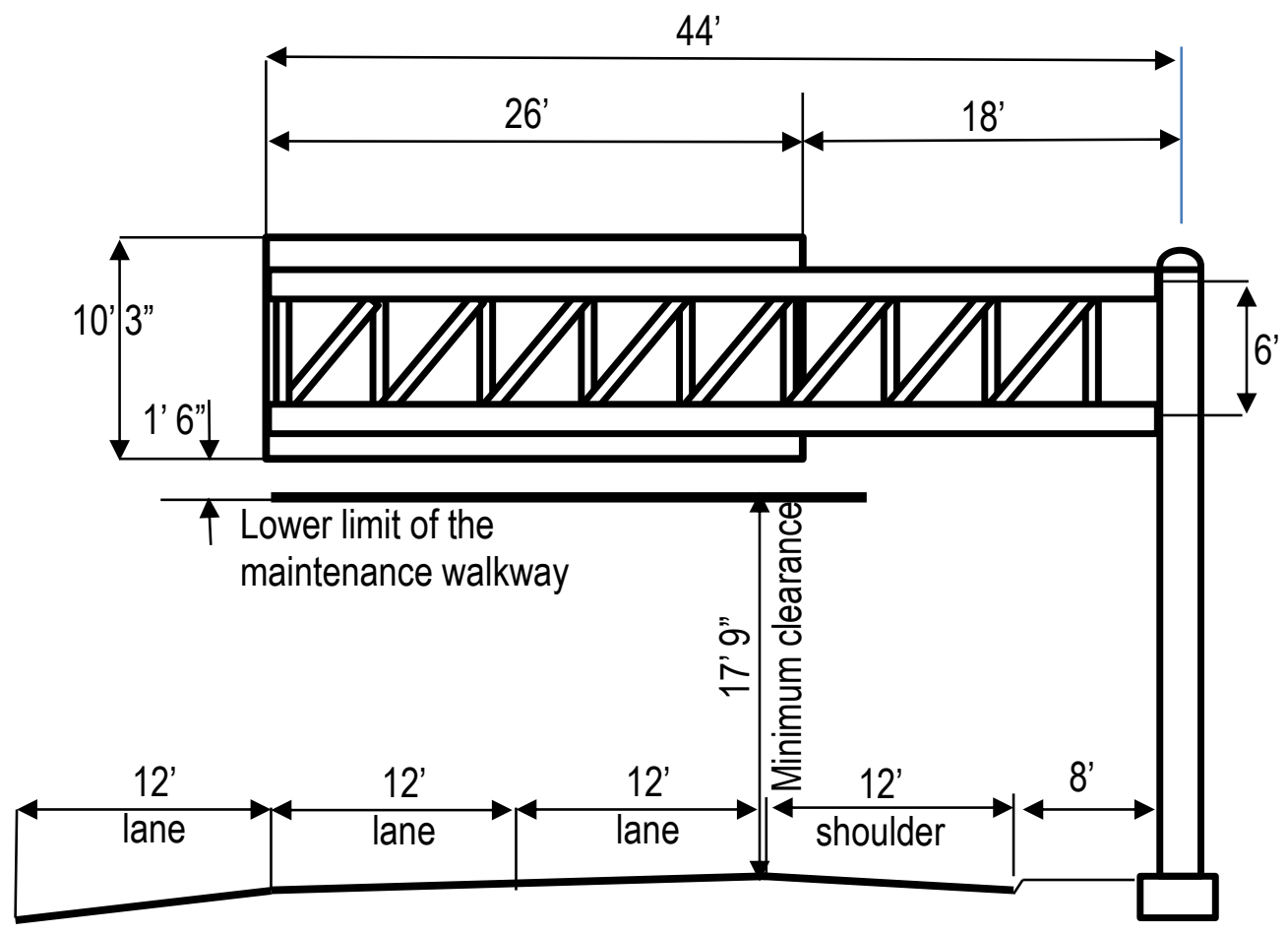

Figure 4-12: Geometry of the TFHRC sign and its location over the highway lanes

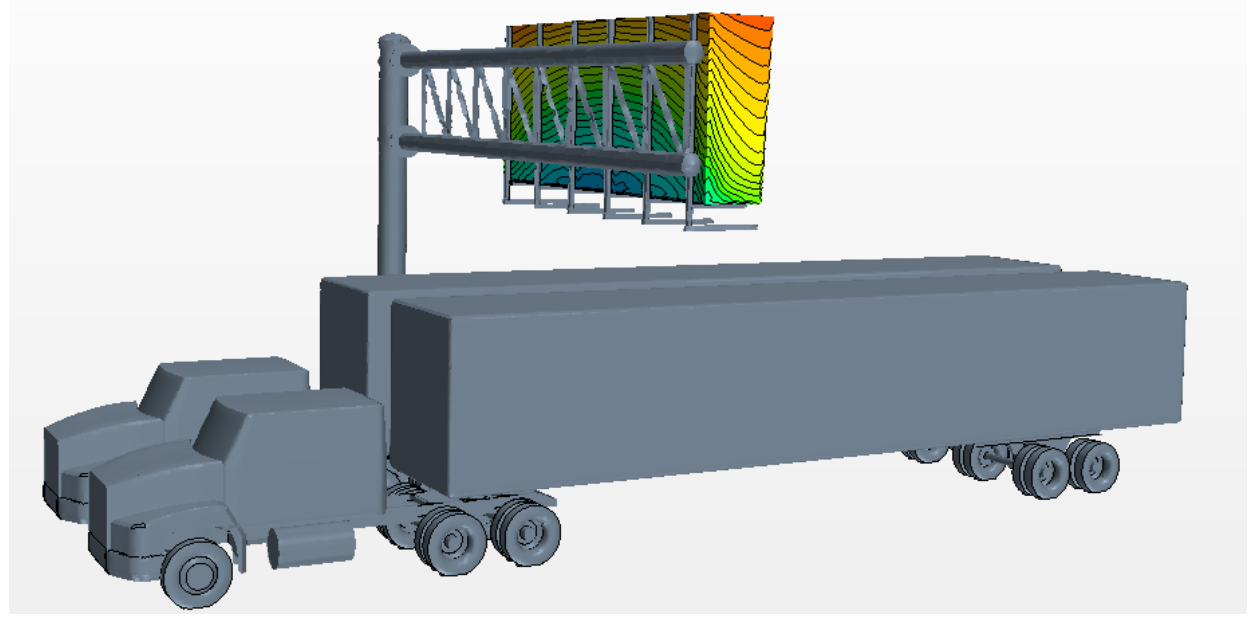

Figure 4-13: Worst case scenario analyzed - two trucks passing simultaneously under the sign 


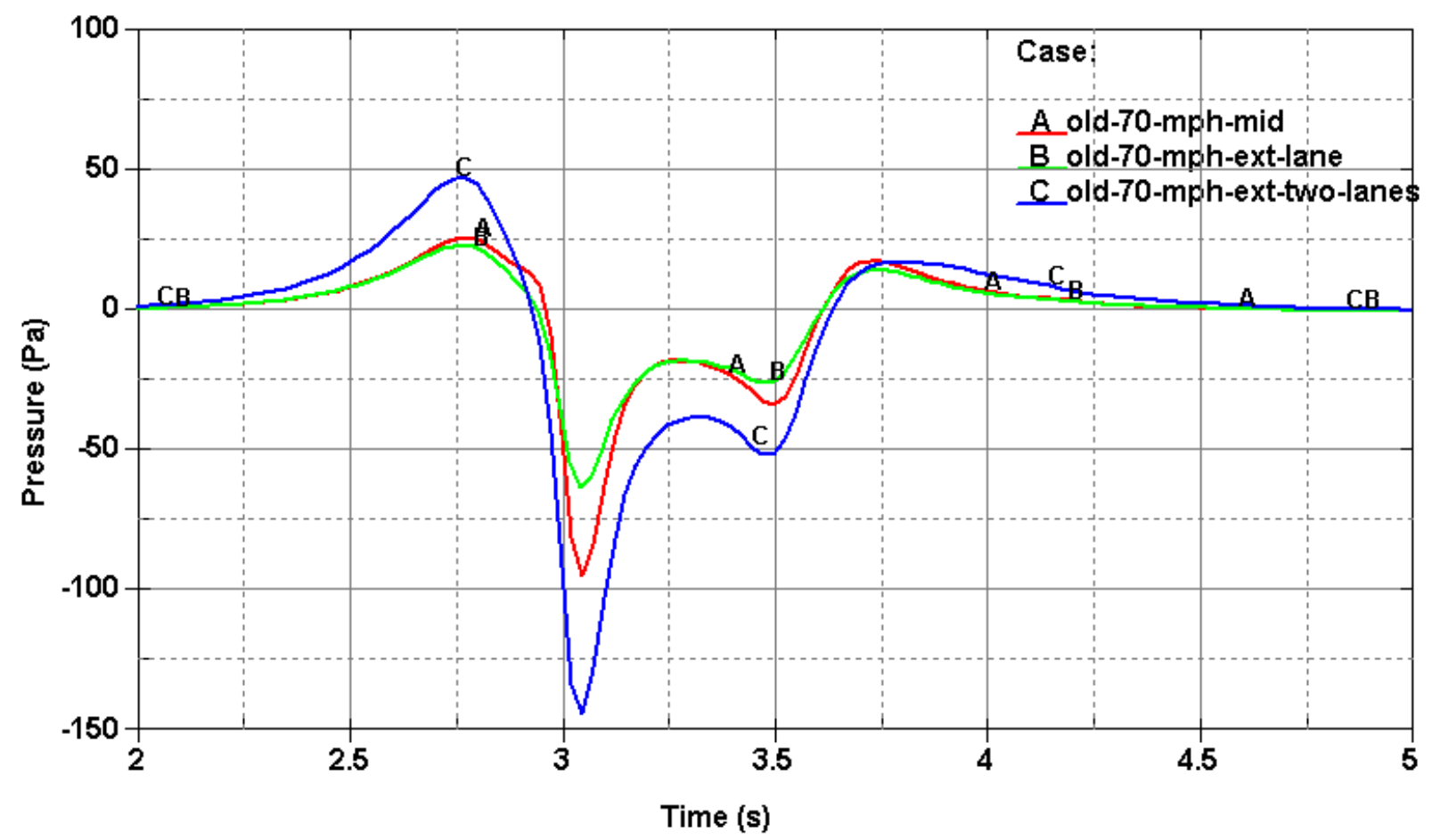

Figure 4-14: Comparison of the pressure histories on the frontal panel due to different truck configuration under the sign

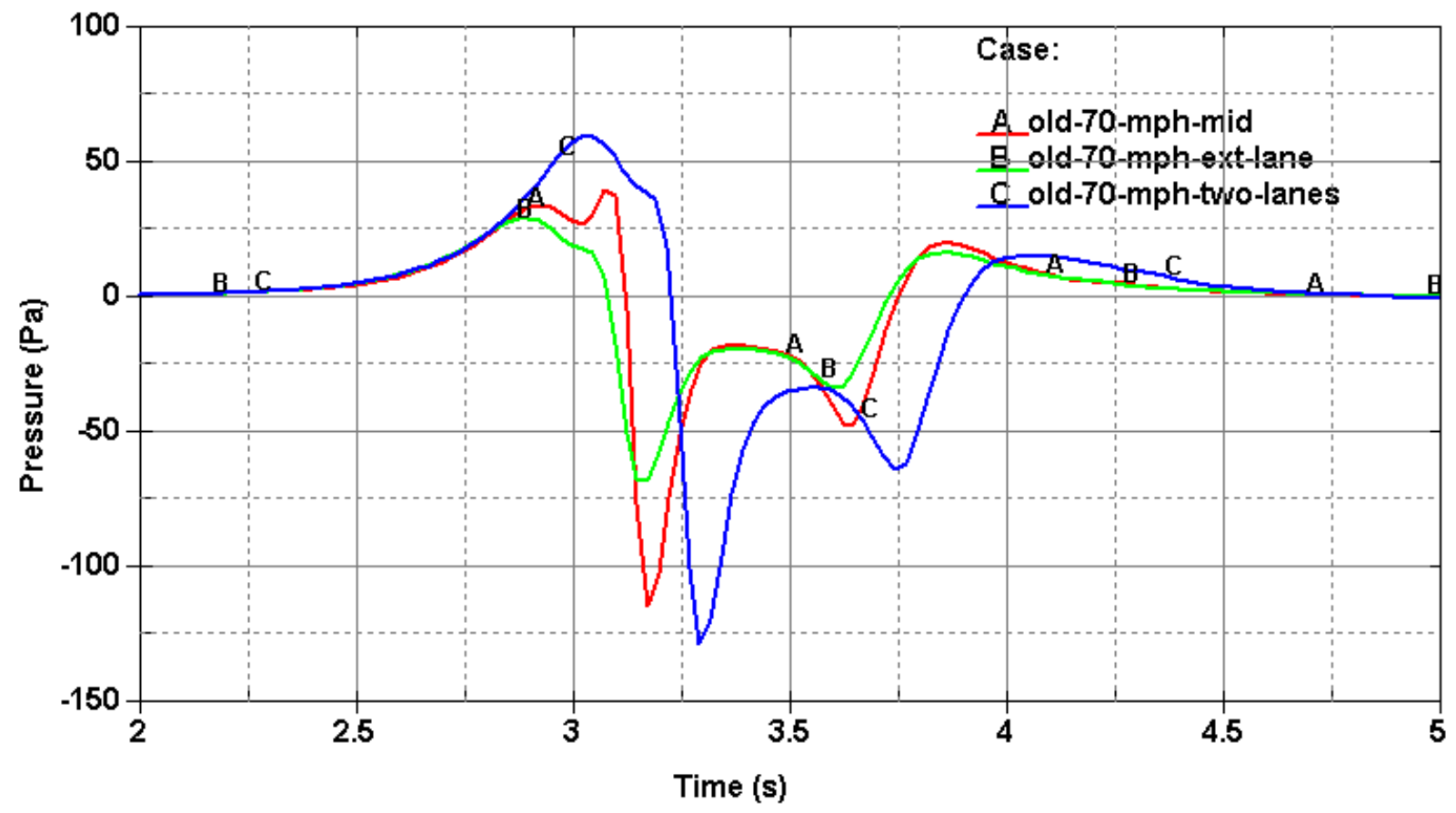

Figure 4-15: Comparison of the pressure histories on the bottom panel due to different truck configuration under the sign 
Figure 4-16 and Figure 4-17 show pressure histories for the case with two trucks traveling side by side and an additional constant head wind with speed of $10 \mathrm{mph}(4.47 \mathrm{~m} / \mathrm{s})$. The wind has visibly contributed to the maximum values of the pressure on the front and bottom panels. The maximum pressure at the measuring point on front panel (element 3145) grew to 183.0 Pa from 144.2 Pa and to $165.3 \mathrm{~Pa}$ from 128.7 $\mathrm{Pa}$ on the bottom panel. The pressure change on the back of the sign was not monitored here but the wind mostly influenced that side of the sign. The following structural analysis was taking into account the pressure distribution on the whole sign box surface.

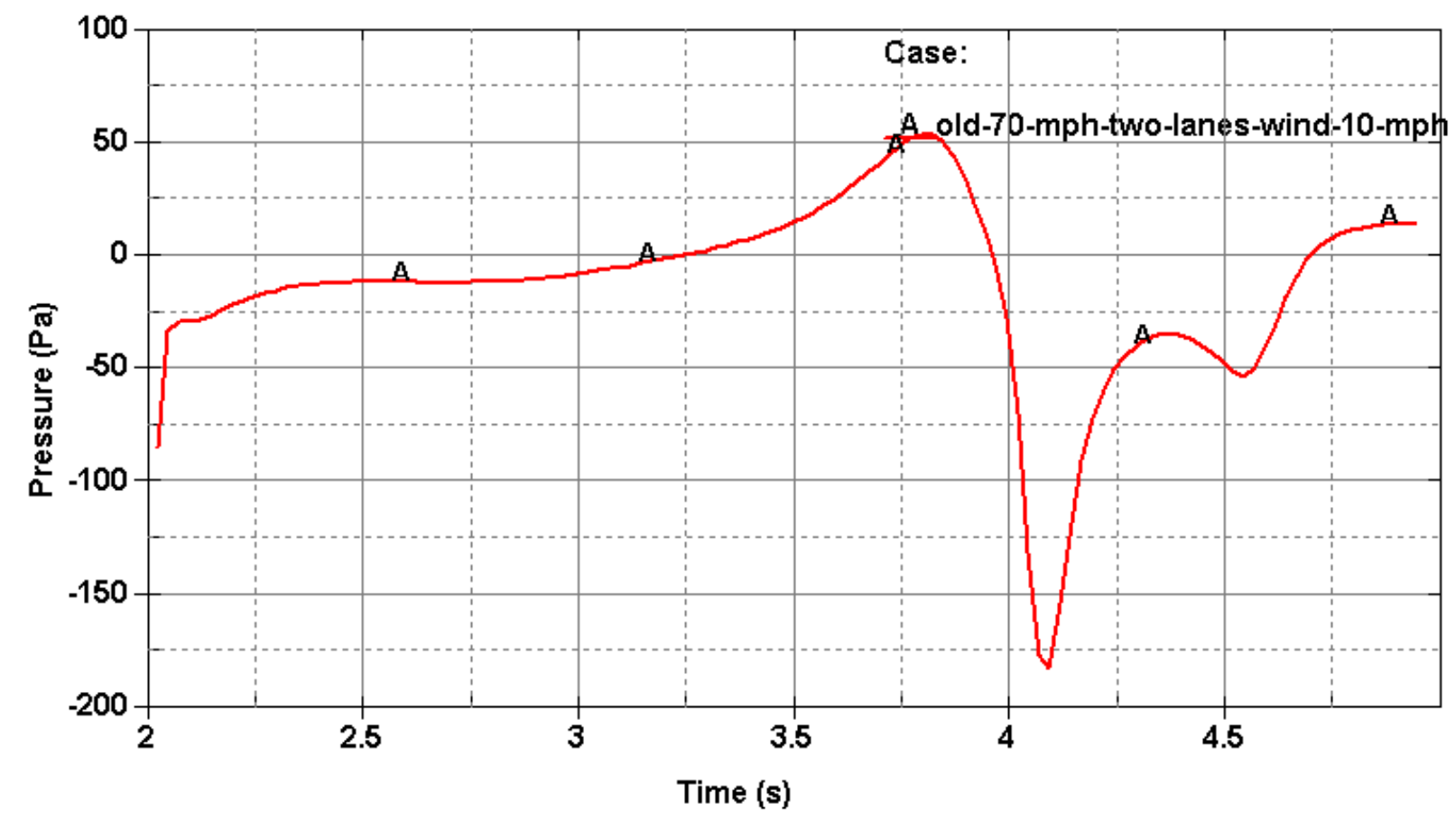

Figure 4-16: Pressure history on the sign frontal panel due to $10 \mathrm{mph}$ head wind and passage of a two trucks under the sign 


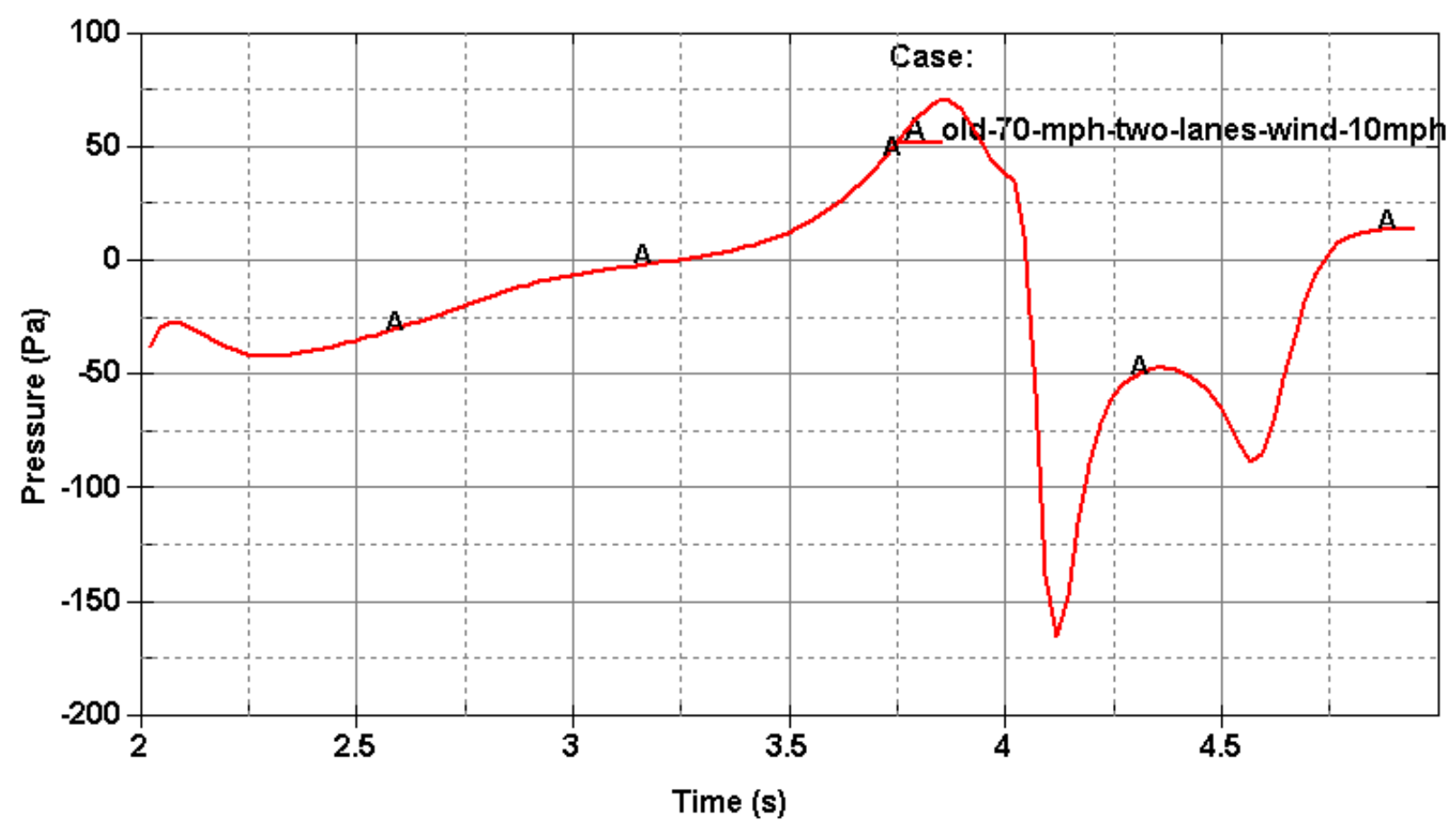

Figure 4-17: Pressure history on the sign bottom panel due to $10 \mathrm{mph}$ head wind and passage of a two trucks under the sign

\section{Results of the Structural Analysis}

In the next step, the pressure history on the sign found in CFD analysis was used in structural analysis of the sign. The analysis aimed at estimating what is the magnitude of deflections (vibrations) in the sign due to the passing trucks. Initially a one way coupling between CFD (STAR-CCM+ software) and Computational Structural Mechanics - CSM (LS-DYNA software) was implemented, meaning the structural analysis in LS-DYNA was performed after the CFD analysis and no feedback from the structural analysis was imposed on the CFD. Python scripting was used to obtain pressure histories for all finite elements in the sign structure from pressure maps found in CFD. That produced 7,500 pressure histories out of 125 pressure maps for 3.125 sec of relevant data.

As a first set of simulations an eigenvalue analysis was performed on the simplified sign structure. The LS-DYNA finite element model was built based on shell elements. At the time the model was built, all structural elements of the cantilever structure supporting the sign were well described, but the exact weight of the sign box and its internal structure was not known. Experimental values of the first two natural frequencies were obtained in the field through a fast Fourier transform (FFT) of the vibration history of the sign in forced pull-down and push-forward tests. The first natural frequency for the twisting mode was estimated to be $0.87 \mathrm{~Hz}$. For the hatchet mode of natural frequency (the second mode) the eigenvalue was estimated to be $1.22 \mathrm{~Hz}$. 
Figure 5-1 shows the first 8 eigenmodes obtained using the numerical (LS-DYNA) eigenvalue solver. The corresponding eigenvalues were as follows: (1) $0.9169 \mathrm{~Hz}$, (2) $1.396 \mathrm{~Hz}$, (3) $2.126 \mathrm{~Hz}$, (4) $2.557 \mathrm{~Hz}$, (5) $3.427 \mathrm{~Hz}$, (6) $3.978 \mathrm{~Hz},(7) 4.579 \mathrm{~Hz}$, and (8) $4.959 \mathrm{~Hz}$. Considering the fact that the sign box was not modeled precisely, i.e. its stiffness was unknown due to lack of knowledge about its internal structure, its mass was not confirmed until later, and the information about the catwalk was not available, the first two eigenvalues were close to the experimental results. These two are related to the global vibration of the cantilever and are of most importance in this study. The model was further used for vibration analysis due to the load exerted by the passing trucks.

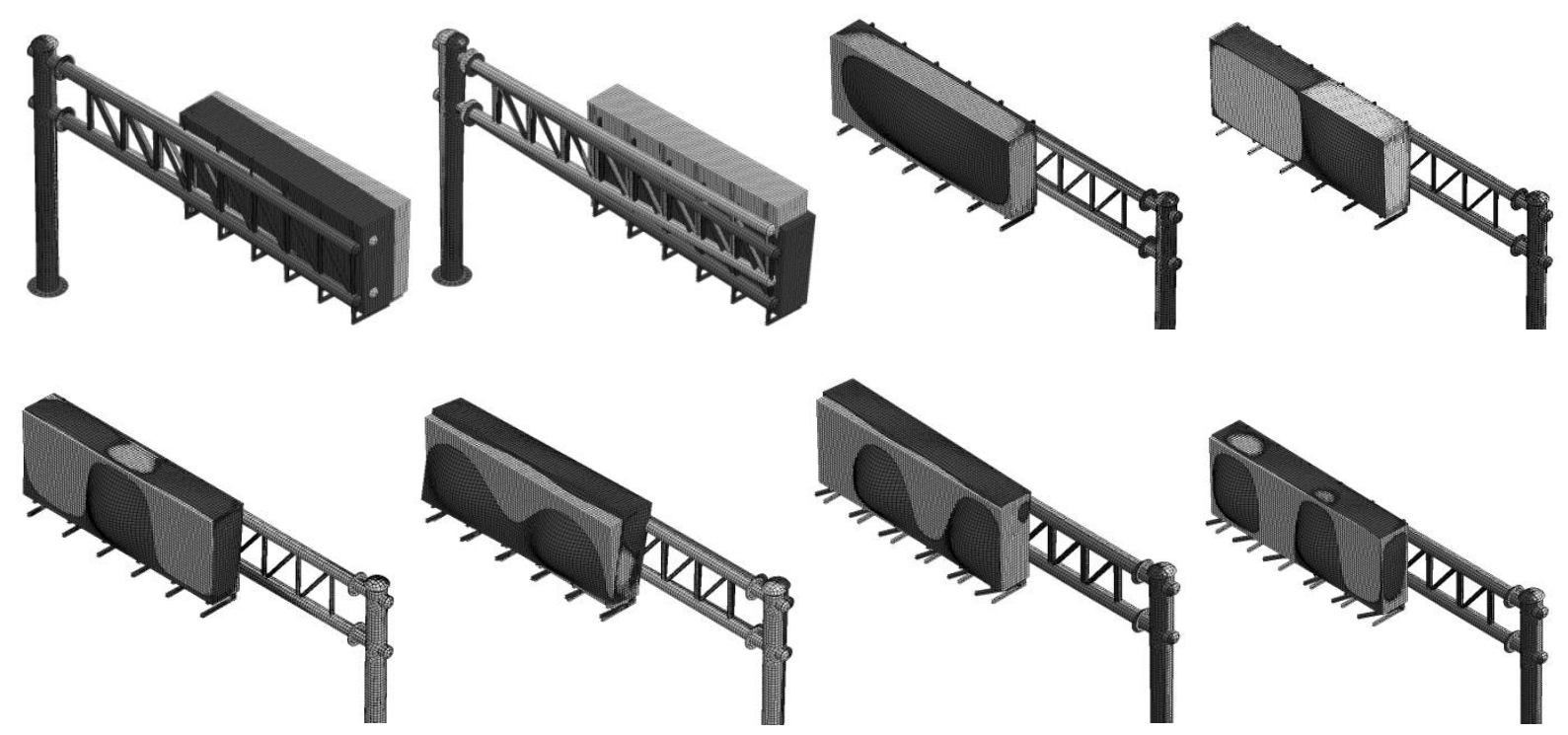

Figure 5-1: Eigenmodes for the TFHRC sign model

The implicit solver with a time step of $0.005 \mathrm{sec}$ was used to analyze the vibrations of the sign due to different loads. The model consisted of approximately 20,000 finite elements modeled with elastic material. As mentioned before, the loading pulses from CFD lasted no longer than 3 sec. However, for most of the runs 60 seconds of real time were simulated.

Similar to the real experiment, push-forward and pull-down tests were simulated to find out which vibration modes are excited in such cases. Figure 5-2 shows X and Z components of cantilever tip vibration history due to gravity and push forward force, in X direction, applied for a short time. Figure 5-3 shows the Fourier transform of these curves. An obvious peak can be noted from the transform of the $\mathrm{X}$ component corresponding to the first vibration mode (frequency $0.912 \mathrm{~Hz}$ ). Two peaks can be noted for frequency $1.40 \mathrm{~Hz}$ (second mode) and $2.57 \mathrm{~Hz}$ (fourth mode) for the $\mathrm{Z}$ component. 
(a)

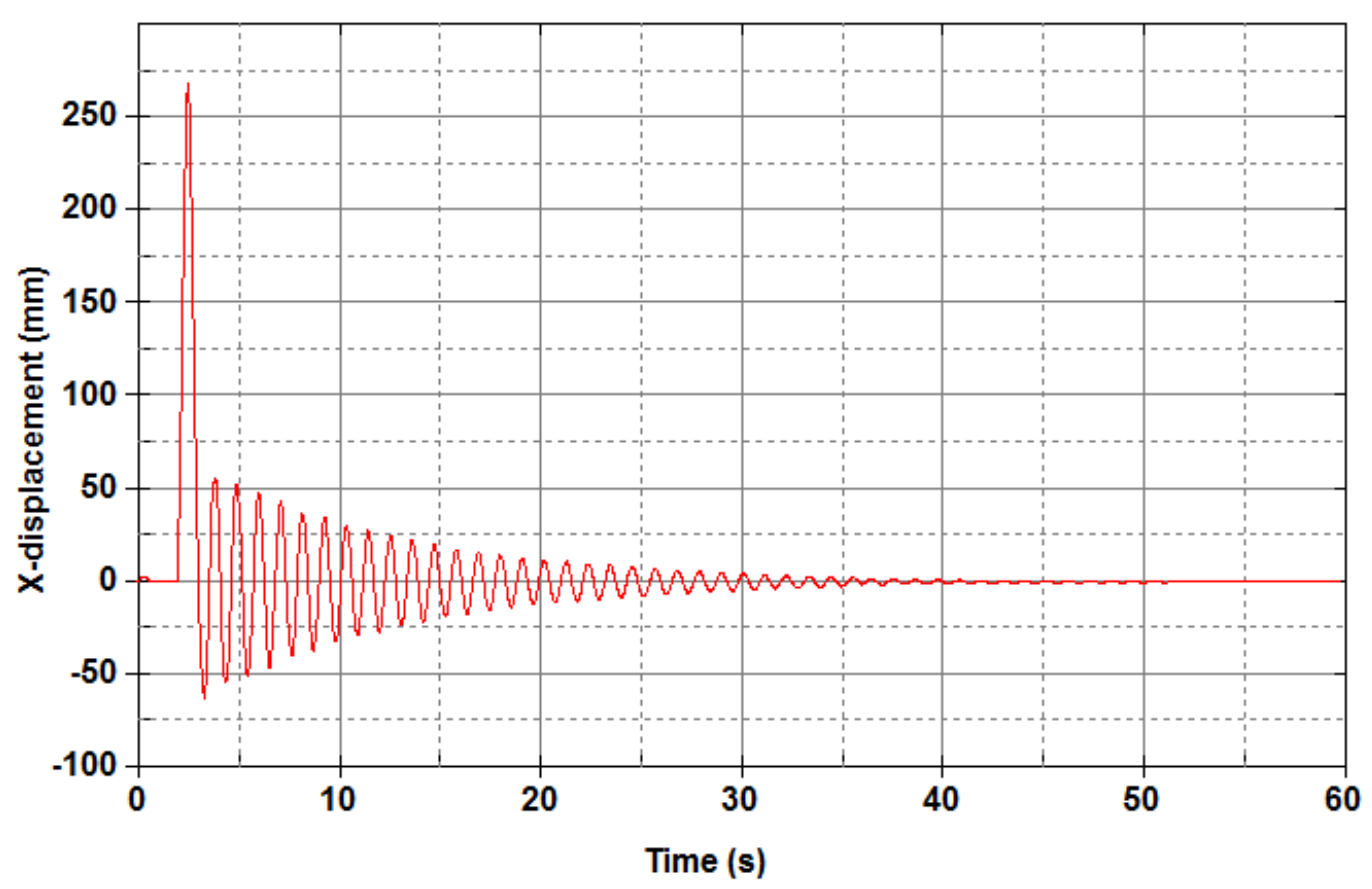

(b)

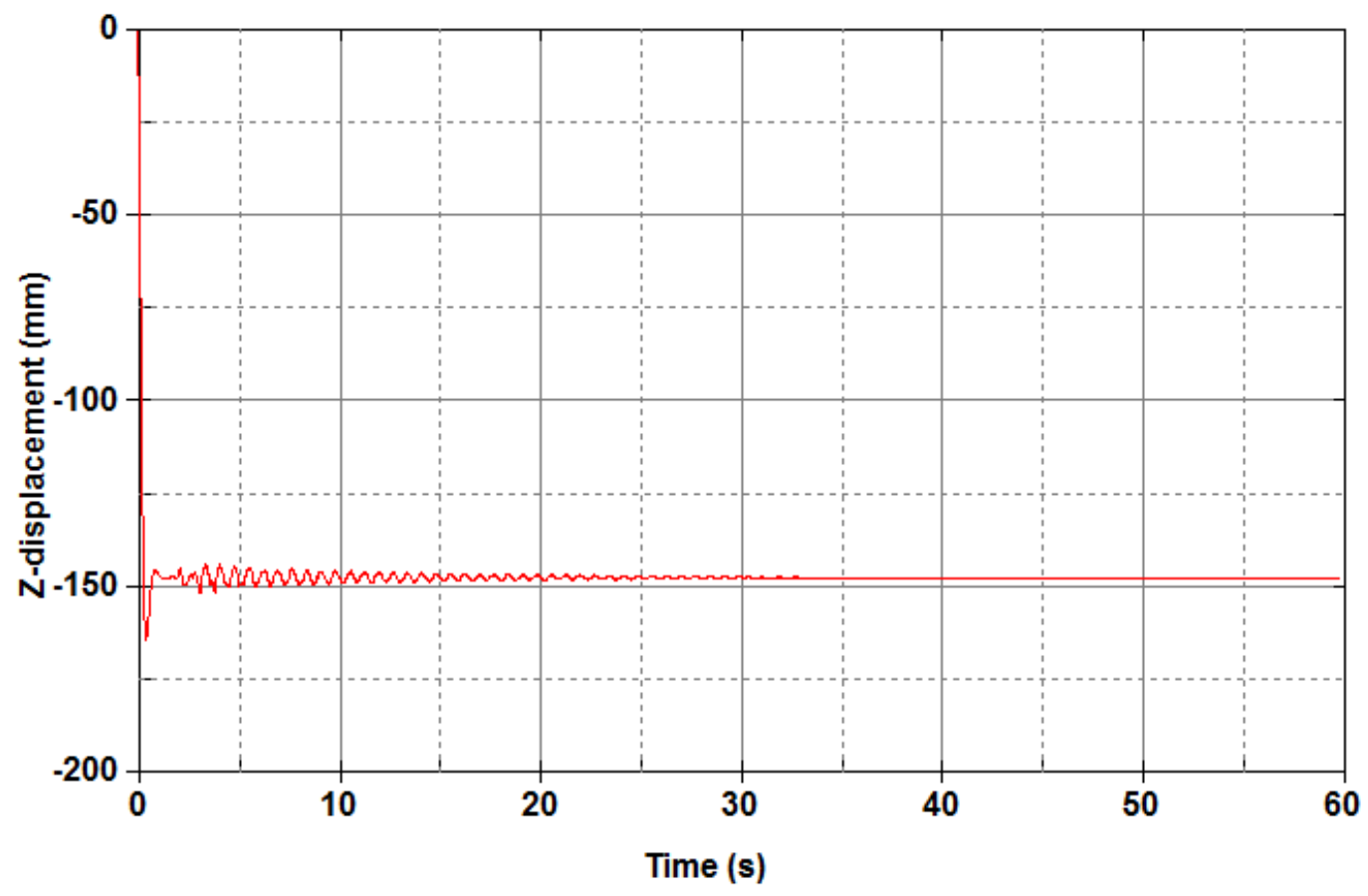

Figure 5-2: Free vibration history of the cantilever tip (a) in the $\mathrm{X}$ direction and (b) in the $\mathrm{Z}$ direction due to gravity and forward force impulse (X direction) 
(a)

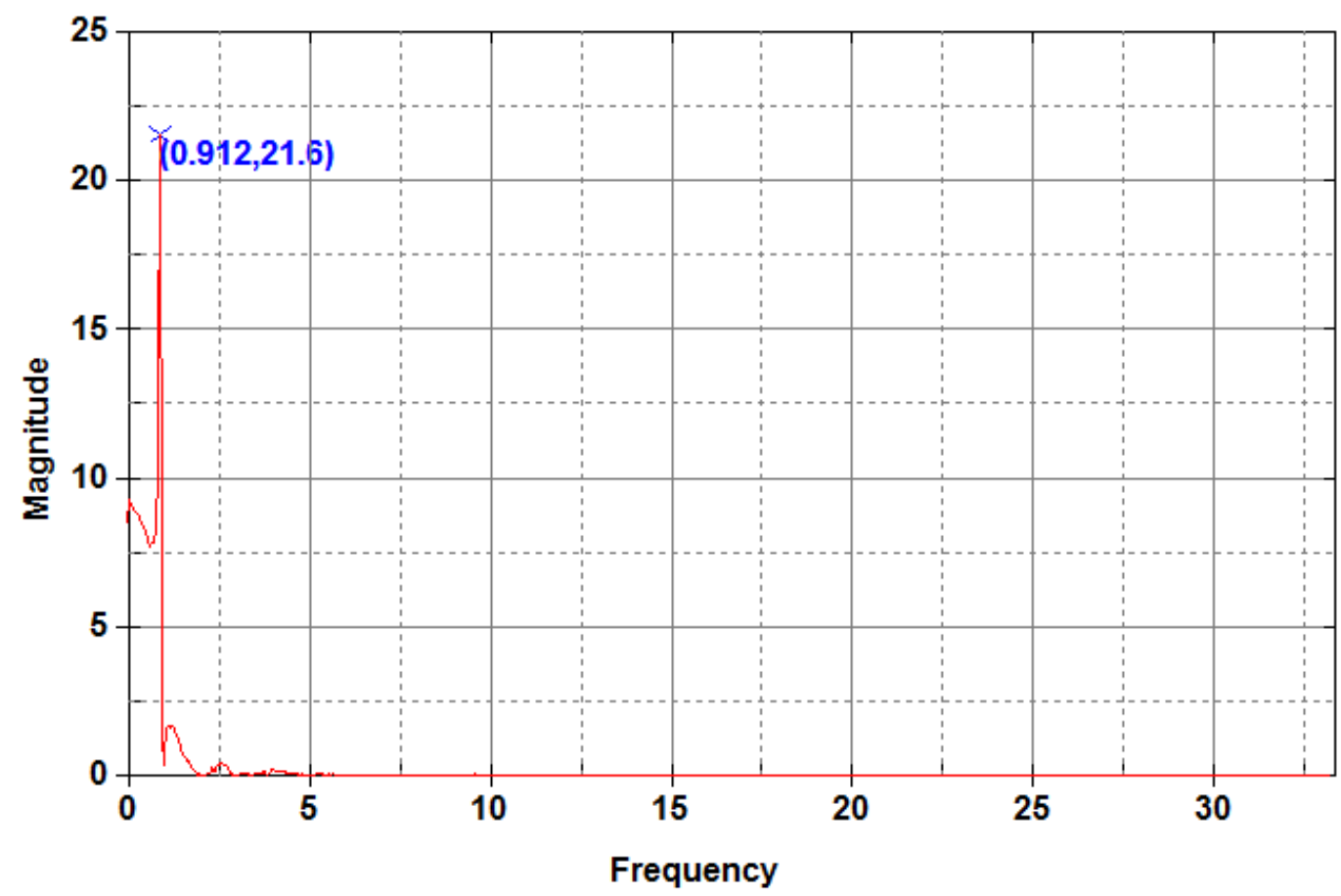

(b)

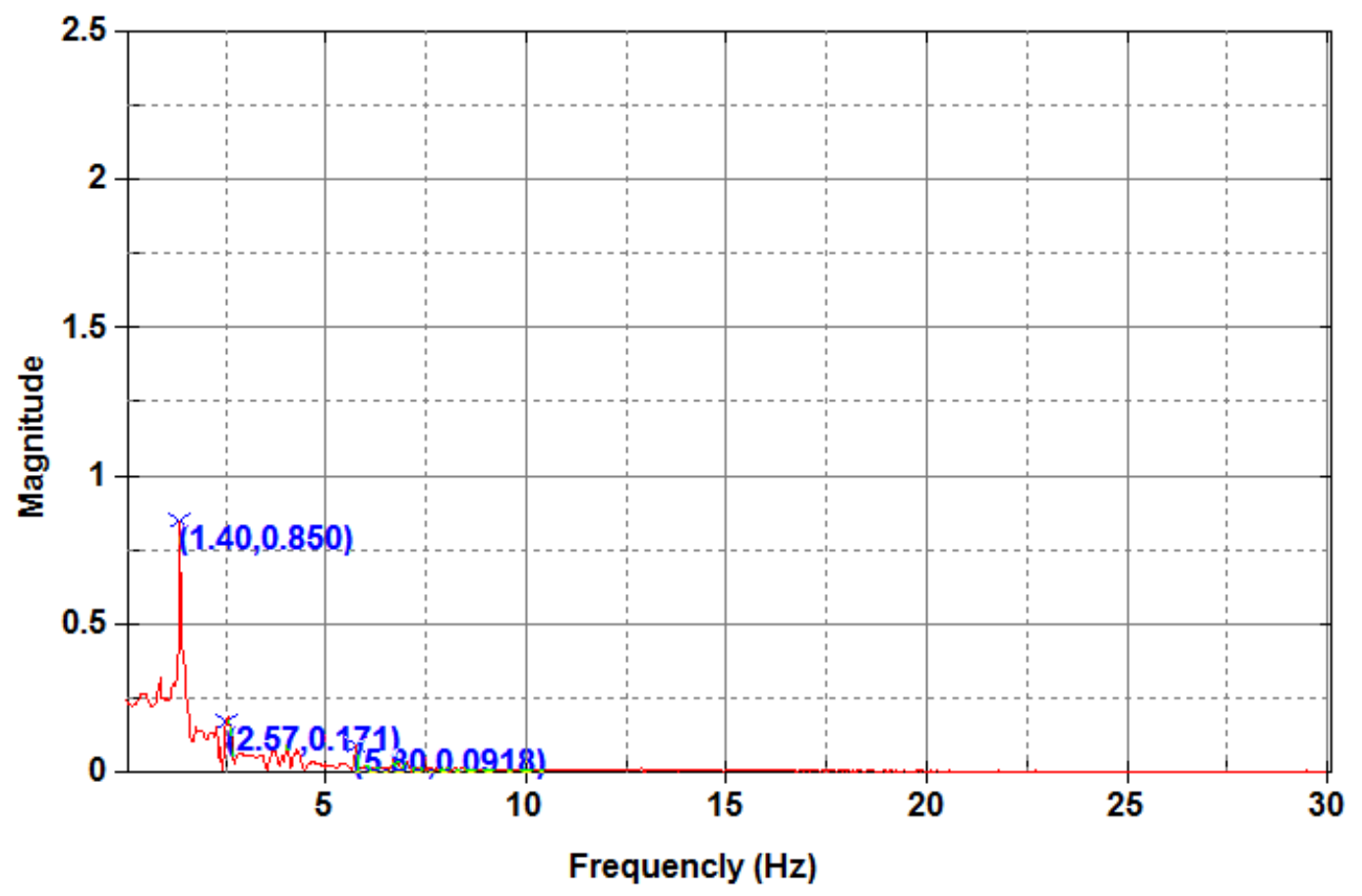

Figure 5-3: FFT of the free vibration history of the cantilever tip (a) in the $\mathrm{X}$ direction (b) the $\mathrm{Z}$ direction due to gravity and forward force impulse (X direction)

For the pull down impulse test a similar analysis was performed. $\mathrm{X}$ and $\mathrm{Z}$ displacement histories were plotted, see Figure 5-4. and their FFT was obtained, see Figure 5-5. This time on both FFTs CFD Estimation of Truck Induced Wind Gusts on Variable Message Signs 
the second natural frequency $1.40 \mathrm{~Hz}$ is noticeable as well as the $2.22 \mathrm{~Hz}$ for the X FFT which may correspond to the third natural frequency. Thus the first four modes of vibration can be expected from a loading pattern similar to the push-forward and pull-down tests.

(a)

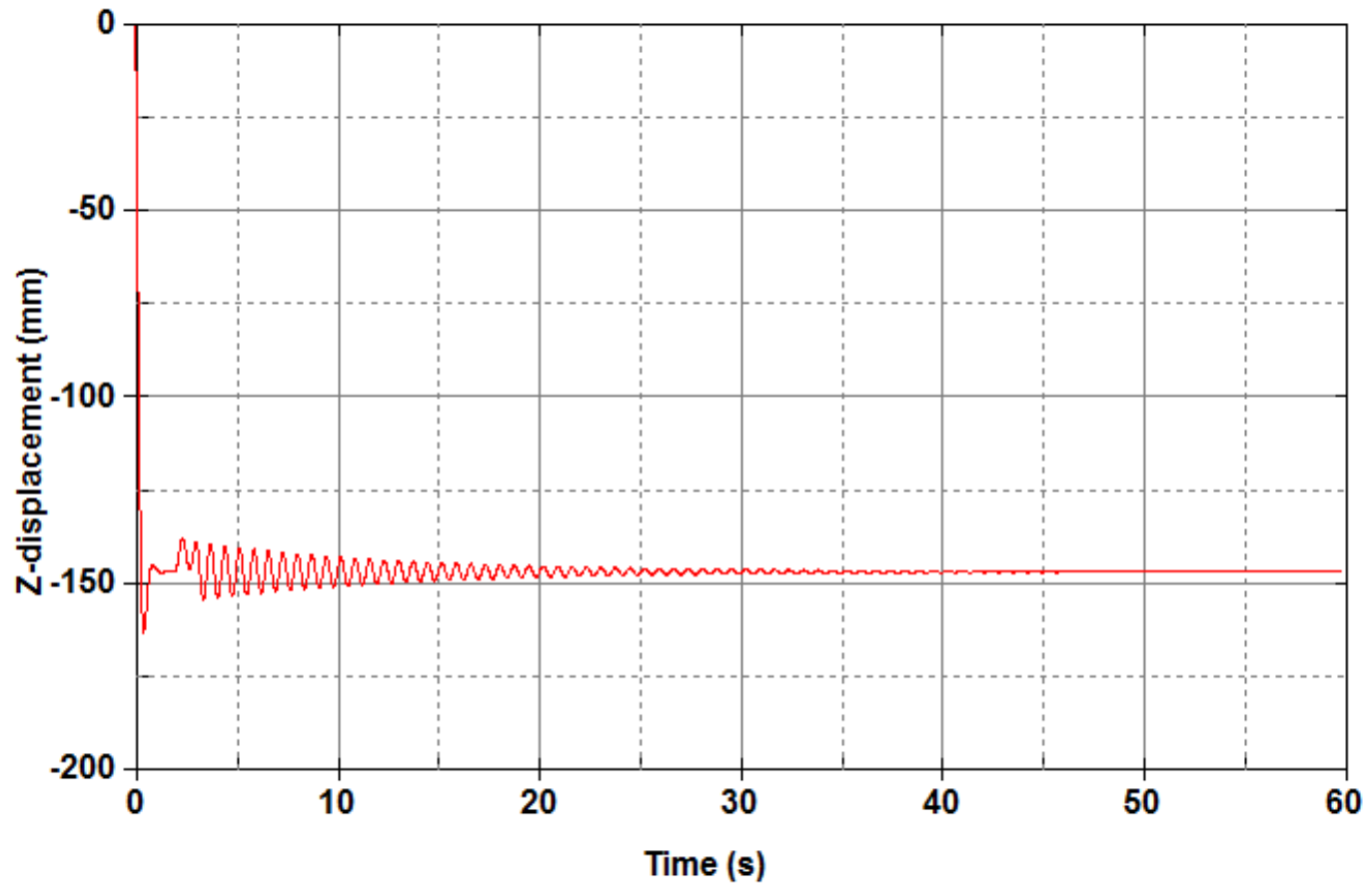

(b)

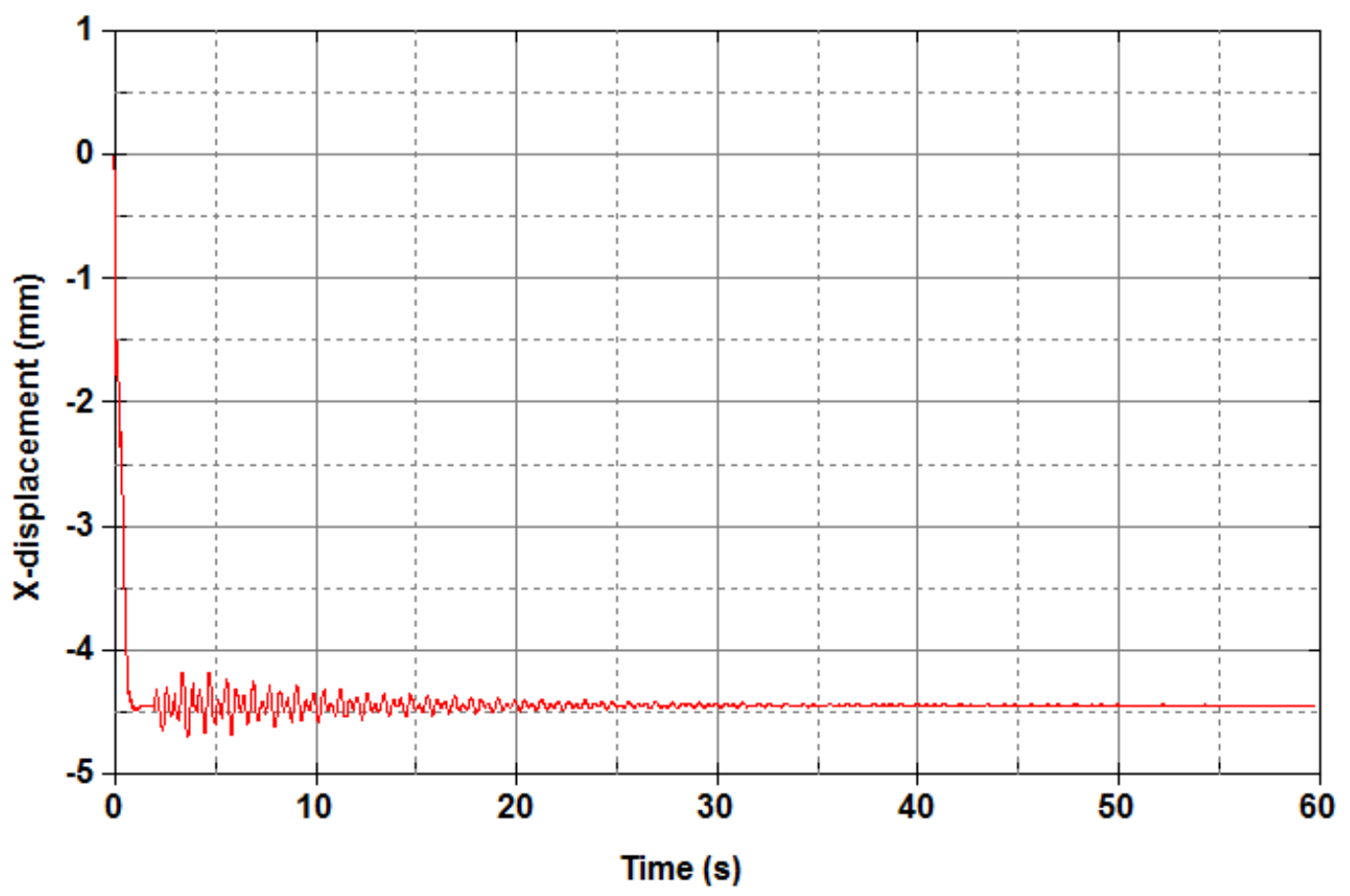

Figure 5-4: Free vibration history of the cantilever tip (a) in the $\mathrm{Z}$ direction and (b) in the X direction due to gravity and pull down impulse (X direction) 
(a)

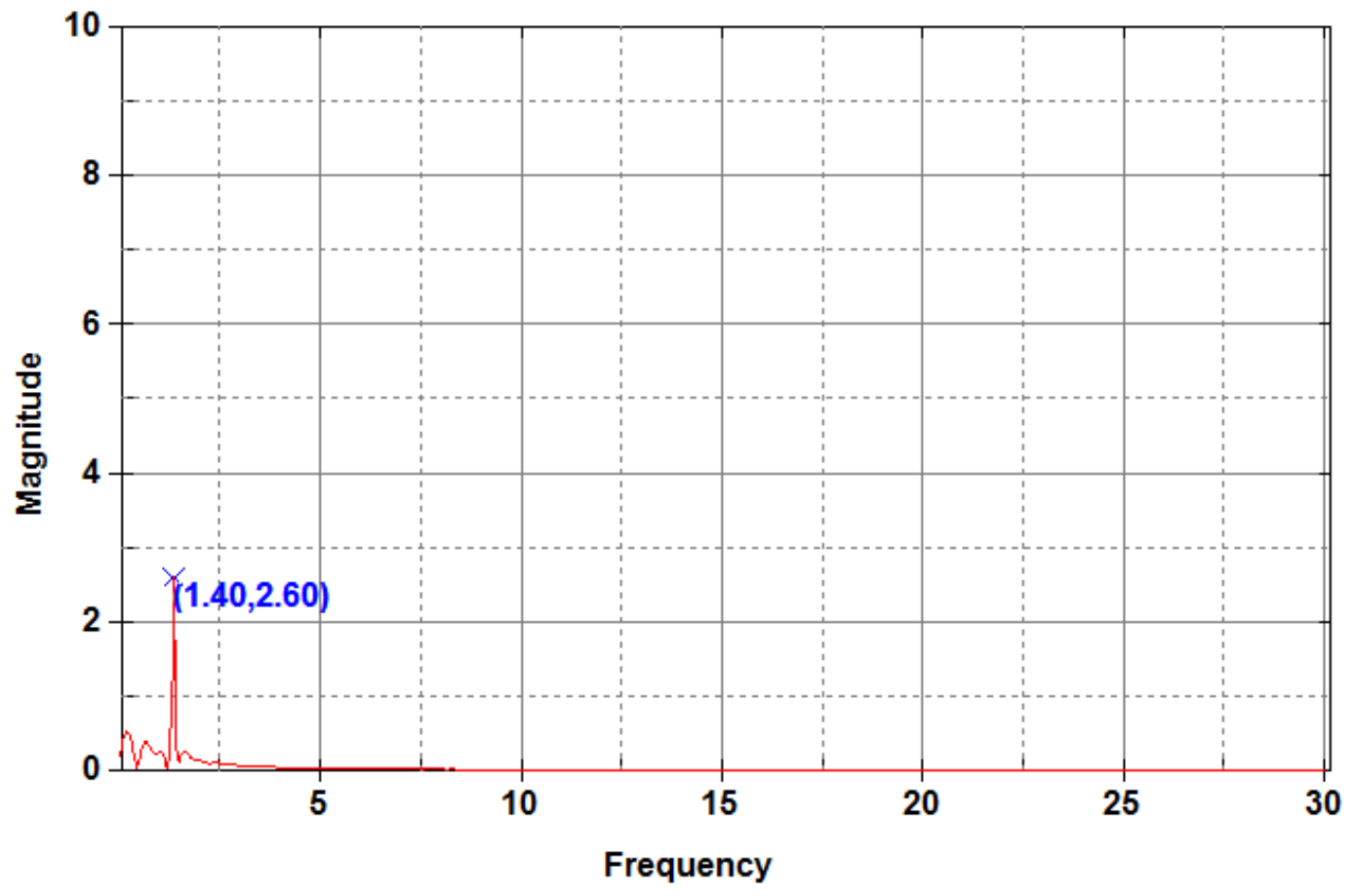

(b)

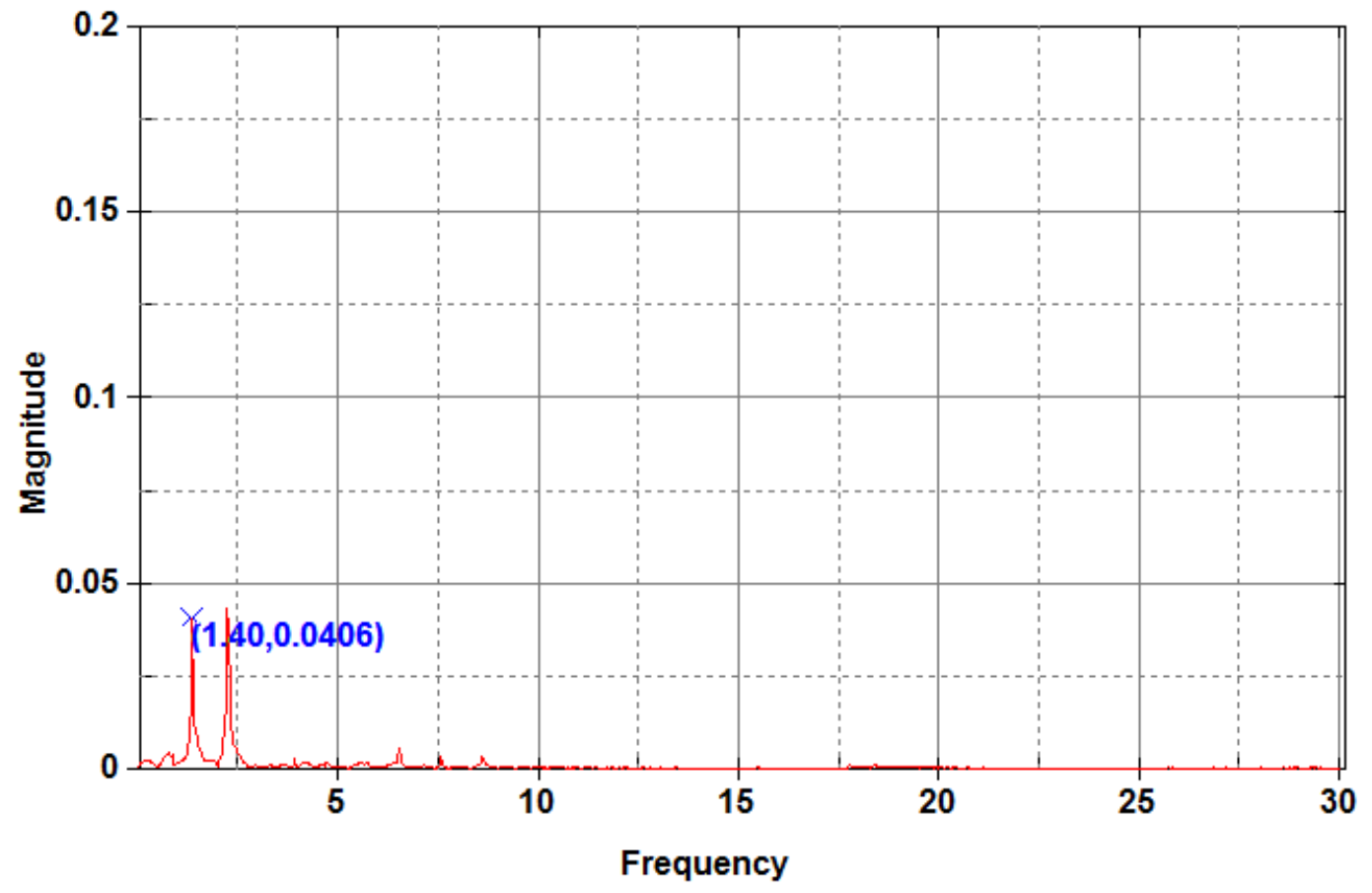

Figure 5-5: FFT of the free vibration history of the cantilever tip (a) in the $Z$ direction and (b) in the $\mathrm{X}$ direction due to gravity and pull down force impulse (X direction) 
A similar analysis has been performed for the loading coming from passage of a single truck. The vibration history for this loading is shown in Figure 5-6. FFTs of these curves are shown in Figure 5-7.

(a)

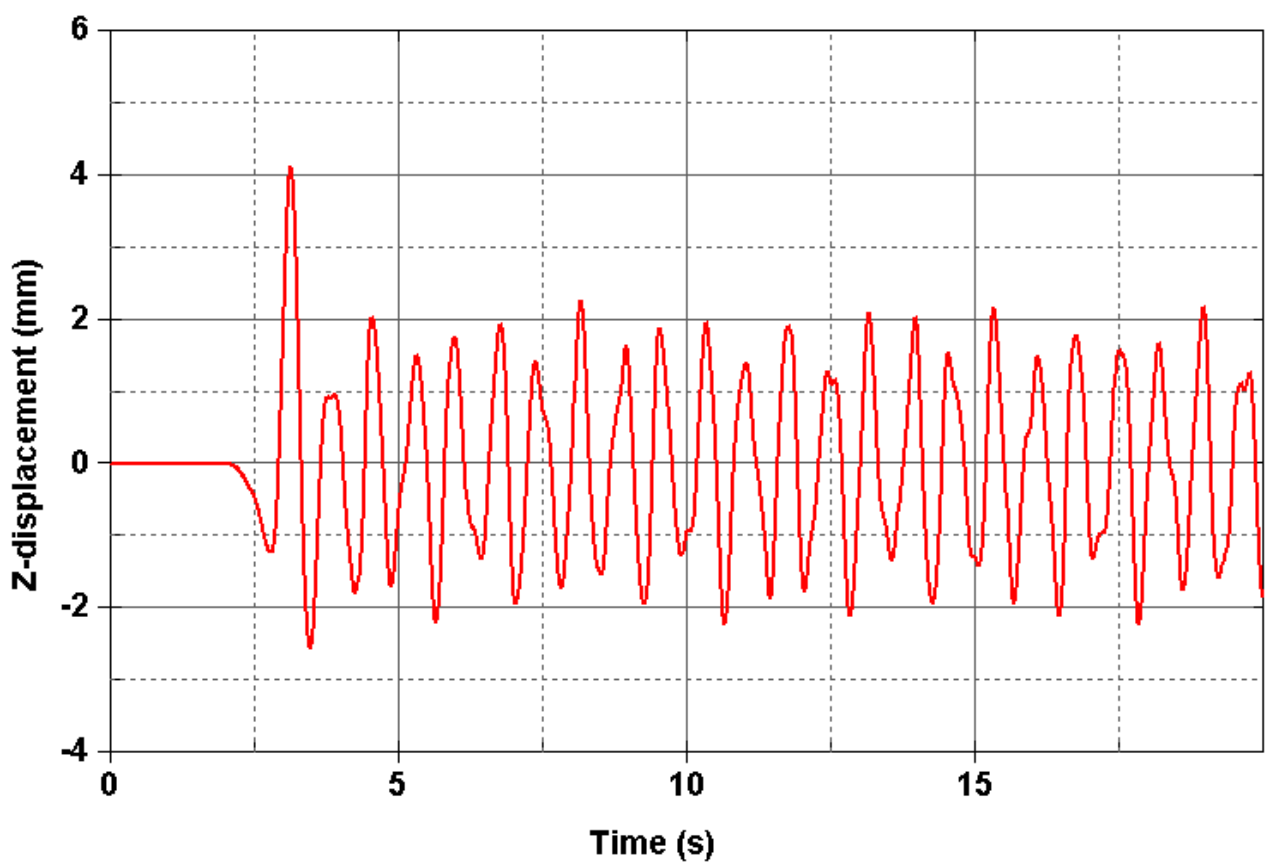

(b)

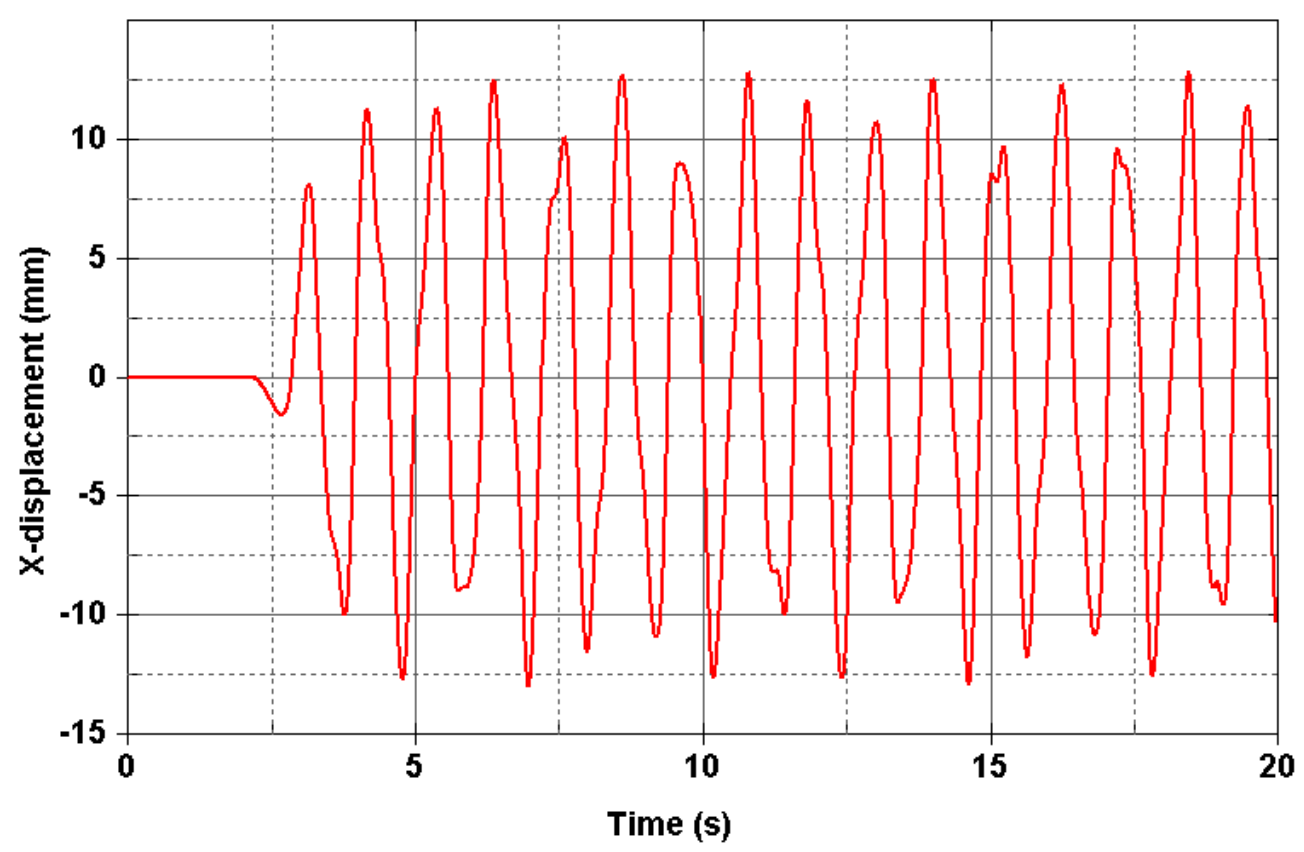

Figure 5-6: Free vibration history of the cantilever tip (a) in the $\mathrm{Z}$ direction (b) in the $\mathrm{X}$ direction due to truck passage

Note that the $1^{\text {st }}, 2^{\text {nd }}, 3^{\text {rd }}$, and probably $6^{\text {th }}$ mode of vibration are excited by this load. However, all the vibration modes associated with local vibration of the sign faces may be spurious and only 
come from the fact that the inner structure of the sign box was not modeled and they are a consequence of assumed stiffness of the box. Nonetheless, the most apparent first two modes pertain to the global vibration modes of the sign.

(a)

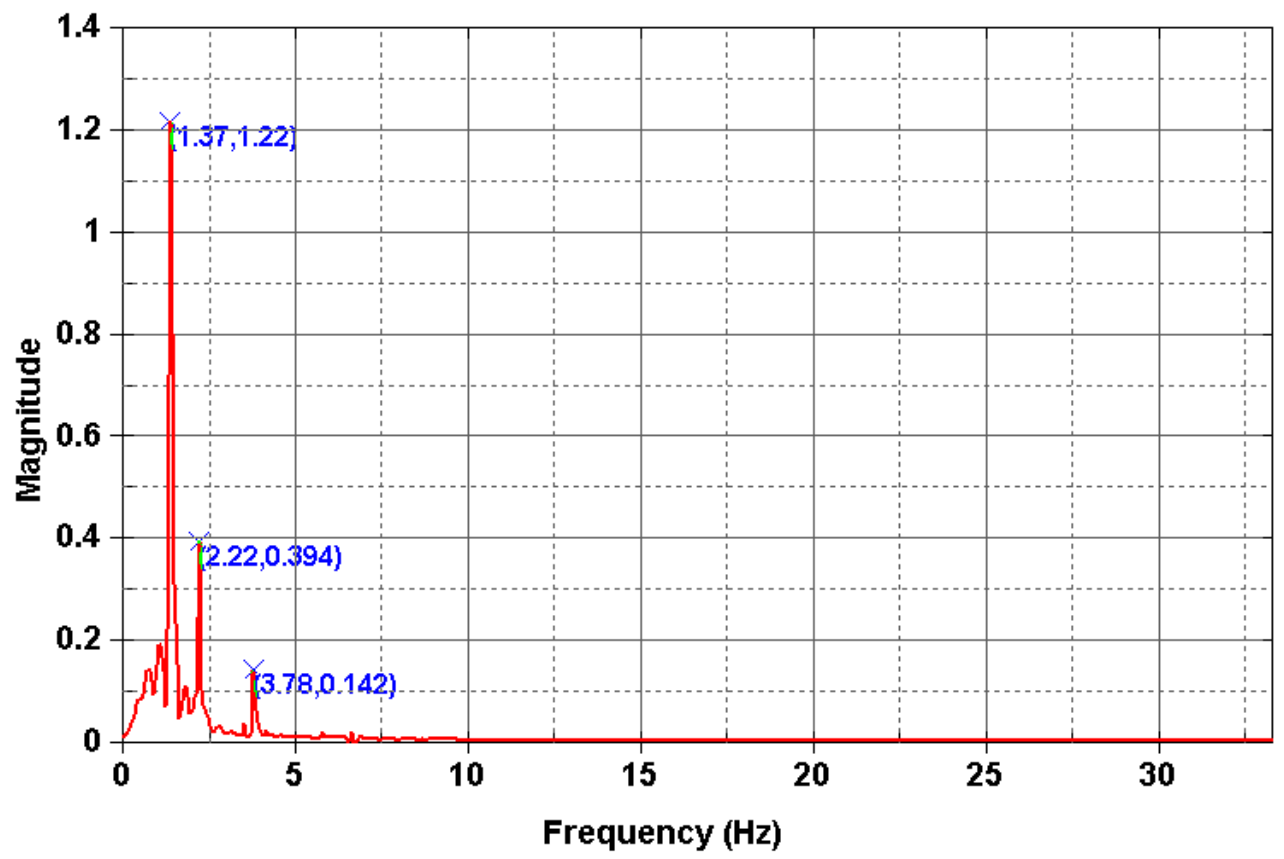

(b)

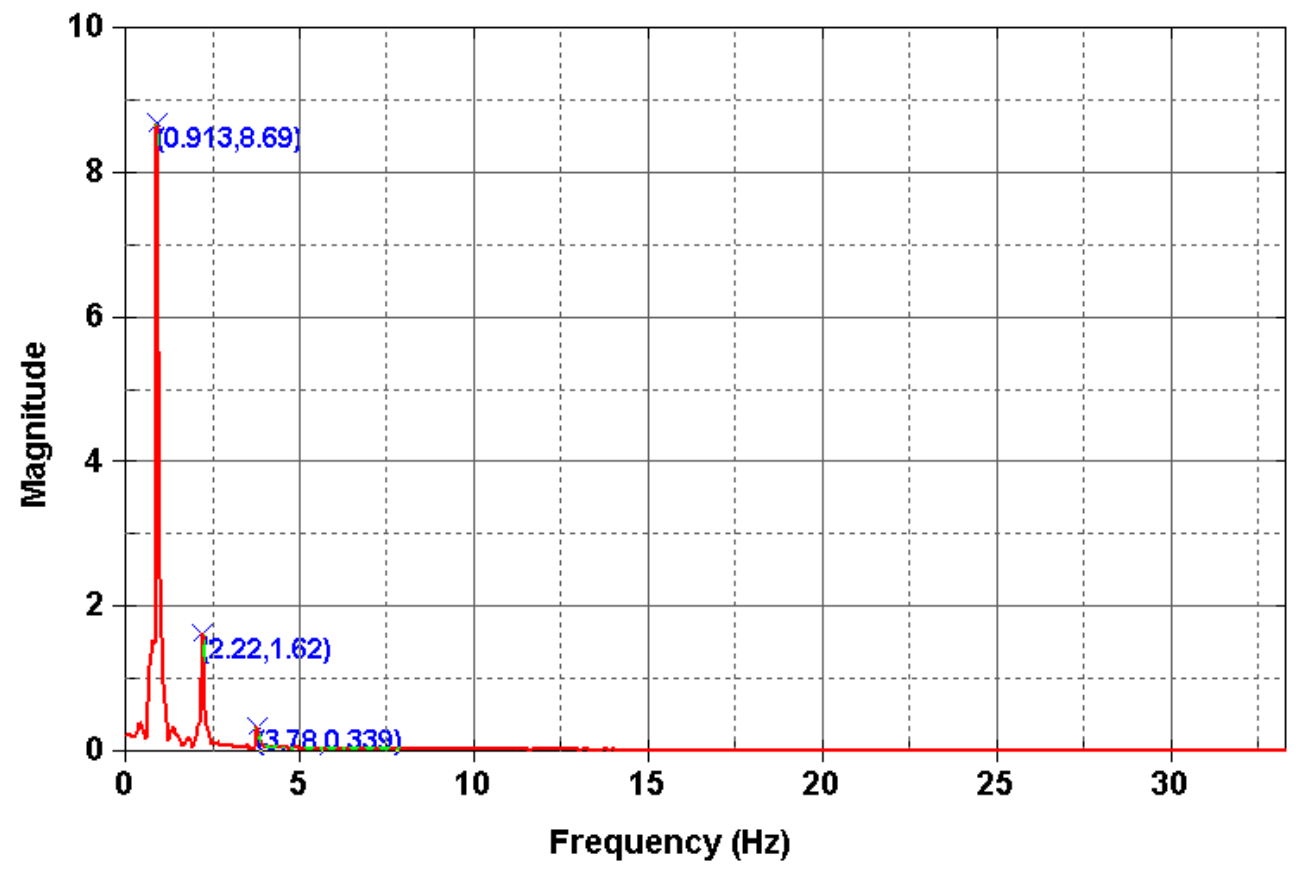

Figure 5-7: FFT of the free vibration history of the tip (a) in the Z direction (b) in the X direction due to truck passage 
After the initial analysis it was already clear that isolated loading from passage of a single truck cannot cause any excessive vibration on the sign. Figure 5-8 presents the vibration history in the Z-direction from passage of one truck. During the first 2 seconds of simulation gravity loading is applied together with large damping to remove any vibrations coming from sudden application of loads. After that the damping is lowered to $1 \%$ of critical damping and the load from the truck is applied. The amplitude of vibrations was less than 1 inch.

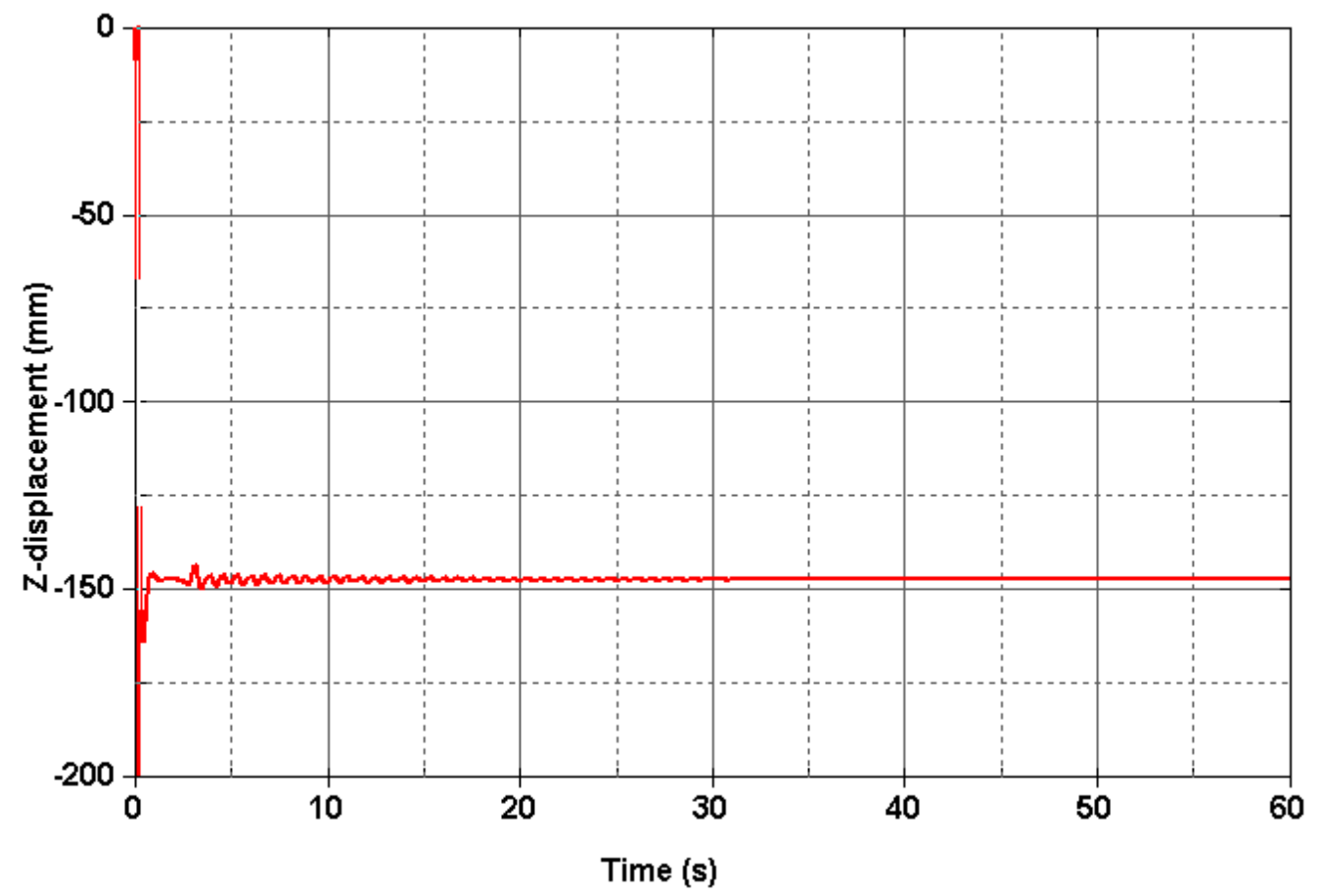

Figure 5-8: Vibration history of the cantilever tip in $\mathrm{Z}$ direction caused by passage of one truck

To see what effect multiple trucks passing under the sign can have, the loading curve from passage of one truck has been used three times with a time offset of $1.4 \mathrm{sec}$ - corresponding to the second natural frequency. Such spacing of the vehicles would be the worst possible case scenario (1.4 sec corresponds to the sign vibration period). Figure 5-9 shows vibration history for the sign tip in the $\mathrm{Z}$ direction from two simulations with and without structural damping. The deflection was larger but still was not higher than 1 inch. 
(a)

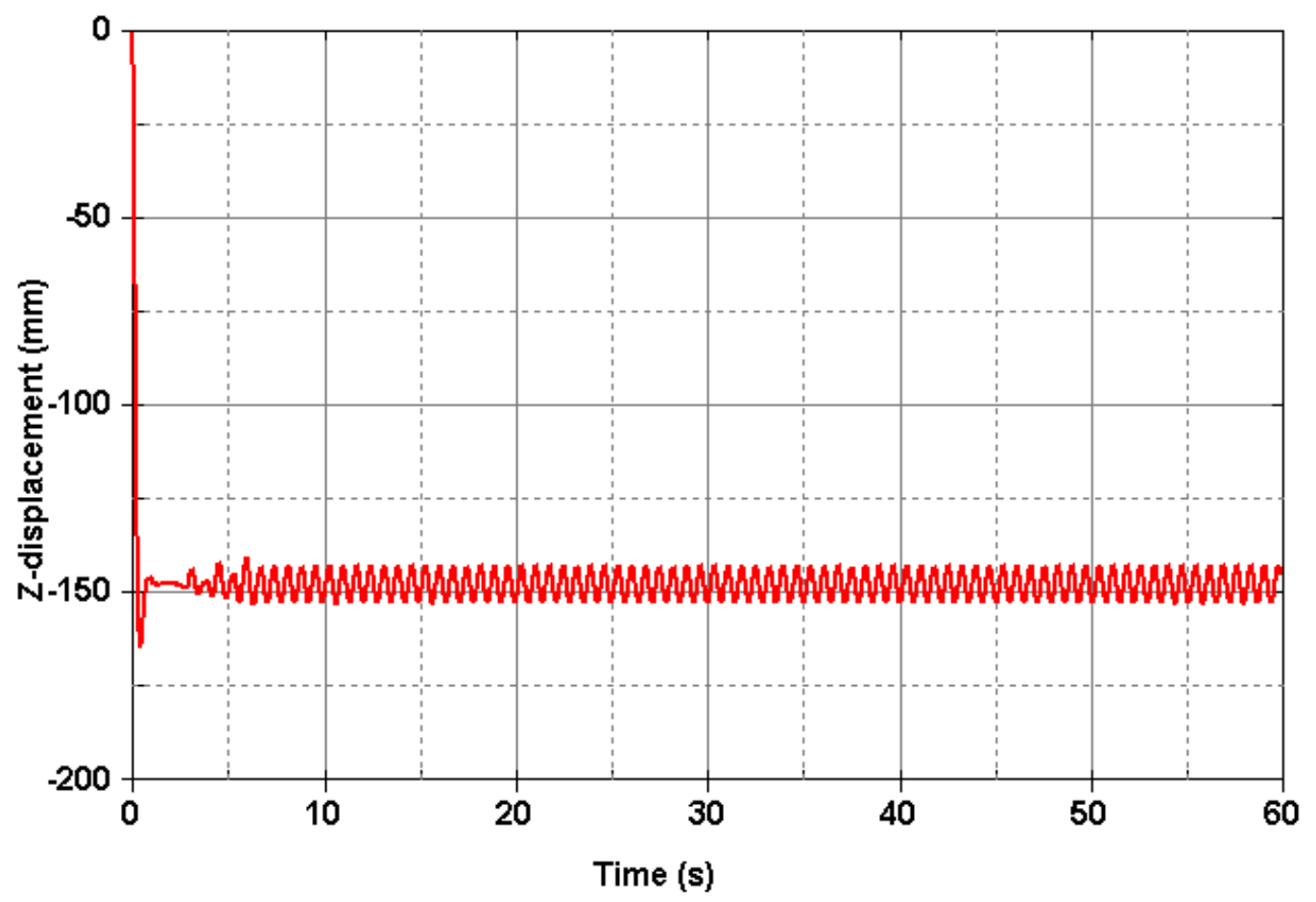

(b)

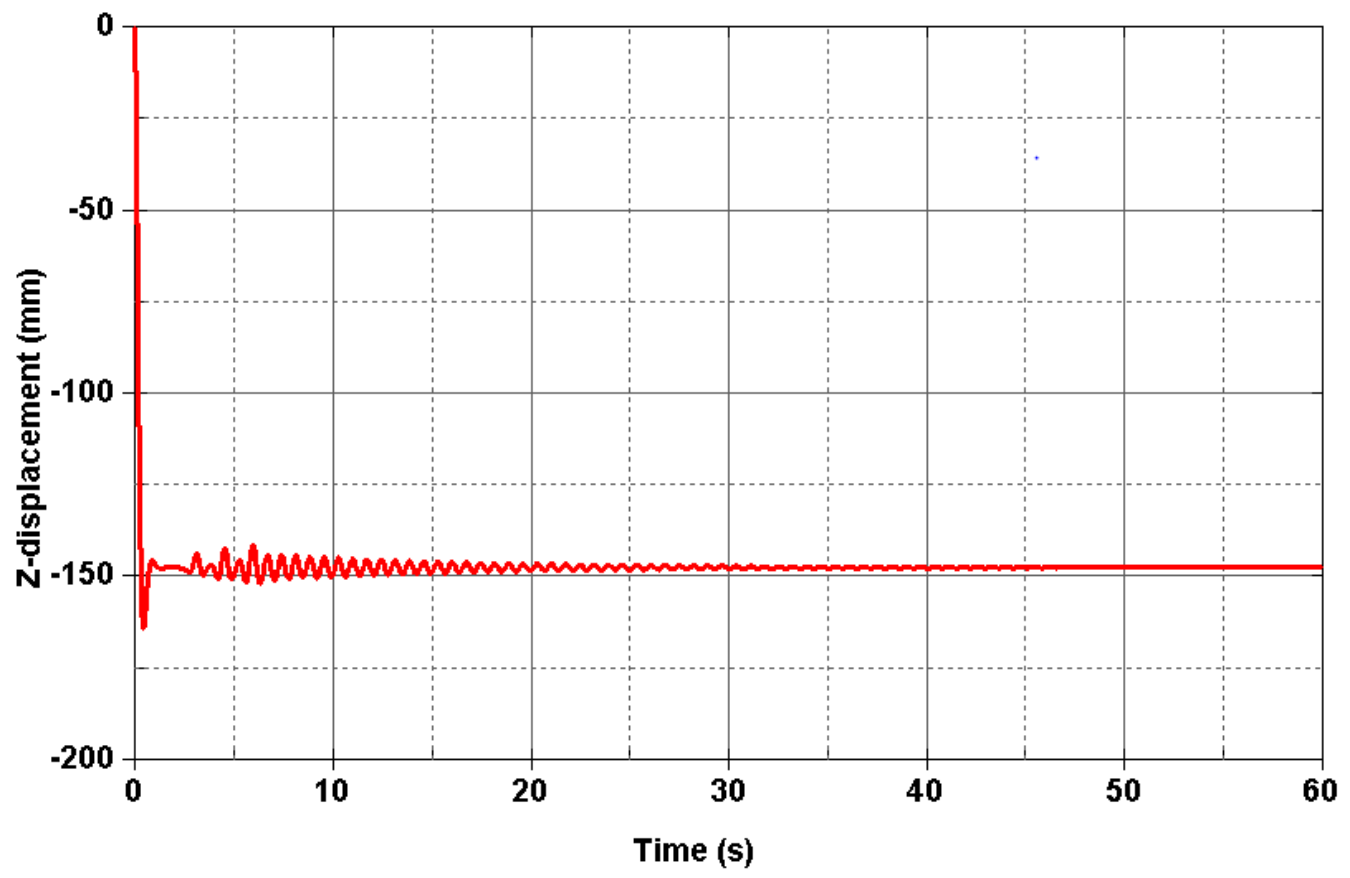

Figure 5-9: Vibration history of the cantilever tip in Z direction caused by passage of three trucks (a) no damping (b) $1 \%$ of critical damping

In the field it was observed that passage of a single truck was exciting the sign with an amplitude of vibrations around 1 foot. From the simulations conducted so far it is clear that the loading CFD Estimation of Truck Induced Wind Gusts on Variable Message Signs 
coming from trucks is not able, on its own, to force such large vibrations. One more, very unlikely event was simulated with the loading coming from 20 trucks passing with exactly the same speed maintaining the worst possible spacing, corresponding to the second natural frequency. The load curves used in this simulation had a shape similar to the one shown in Figure 5-10.

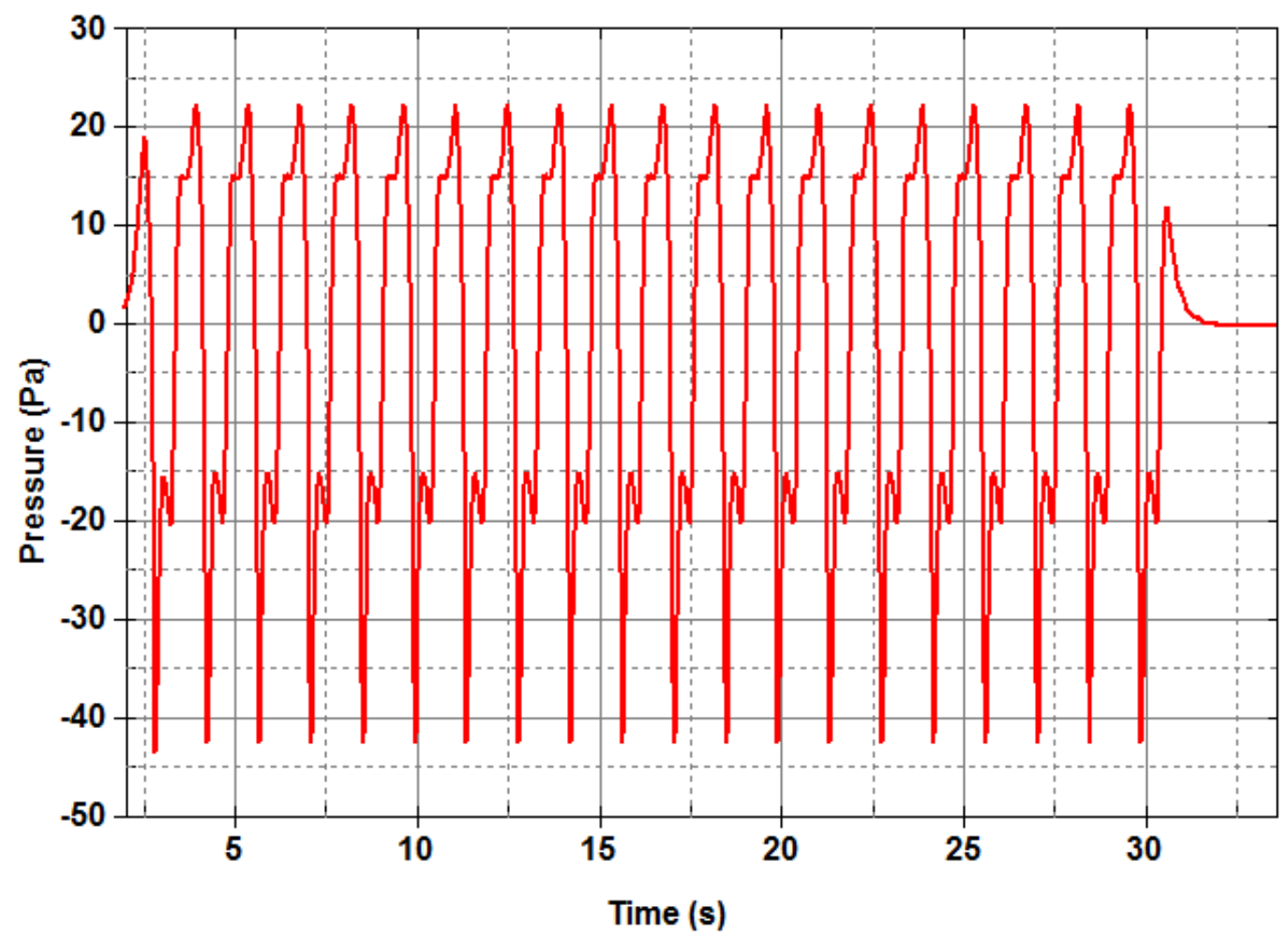

Figure 5-10: Typical pressure history acting on one element of front panel coming from combined load from 20 trucks passing under the sign

Figure 5-11 shows vibration histories for the sign tip in the $\mathrm{Z}$ direction. In the case without damping the amplitude of vibrations was about 2 inches. With the damping it was even smaller. The conclusion drawn from these simulations is that the truck passage on its own cannot excite the sign to the extent reported in the field. One hypothesis for this is that the interaction between the sign and the air has to be modeled in a two way coupling (impact of deforming structure on the air flow needs to be accounted for) and wind action has to be modeled. There is a possible interaction between the loads coming from the wind and the trucks that together may lead to some forms of galloping that were reported in the field. 
(a)

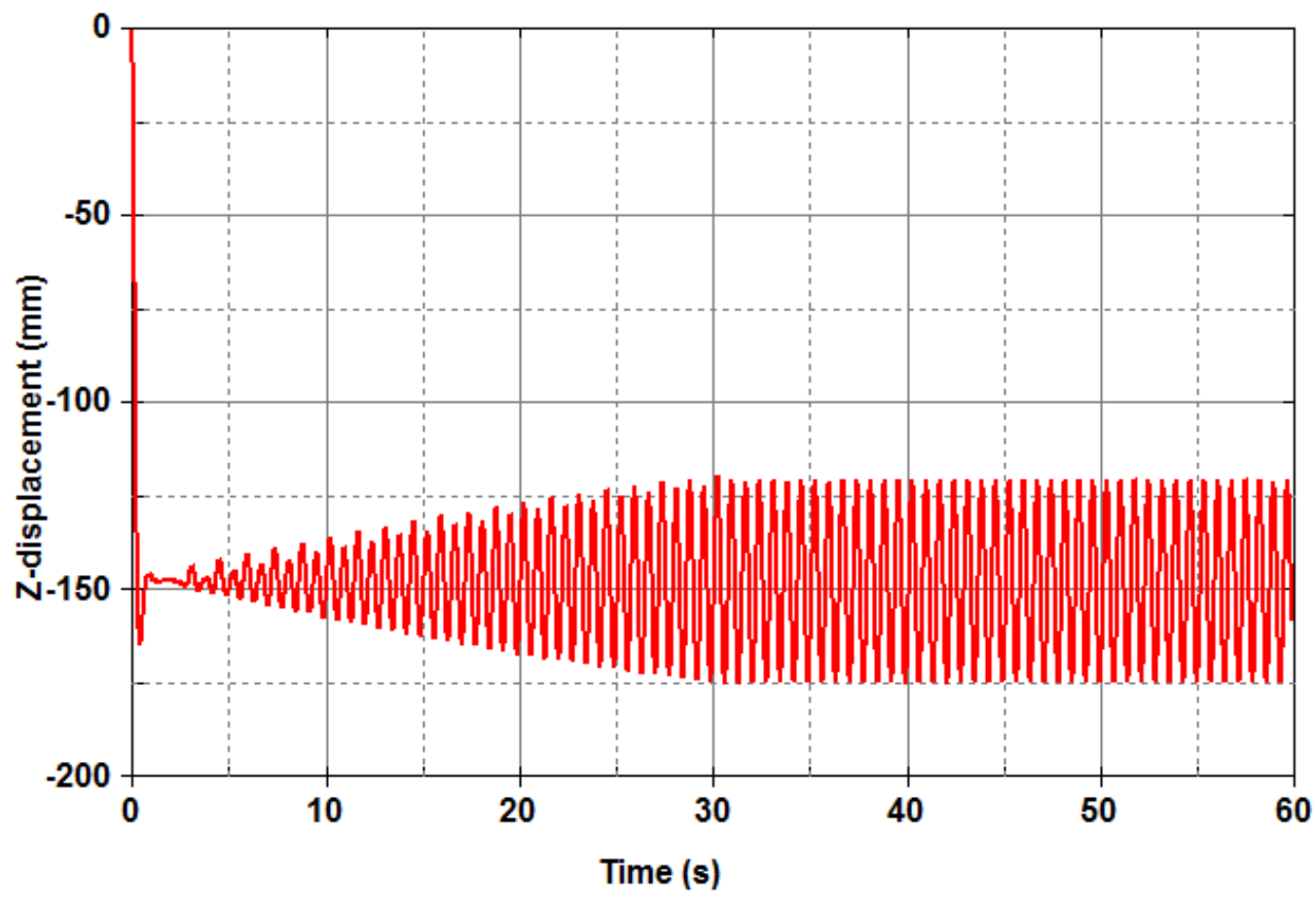

(b)

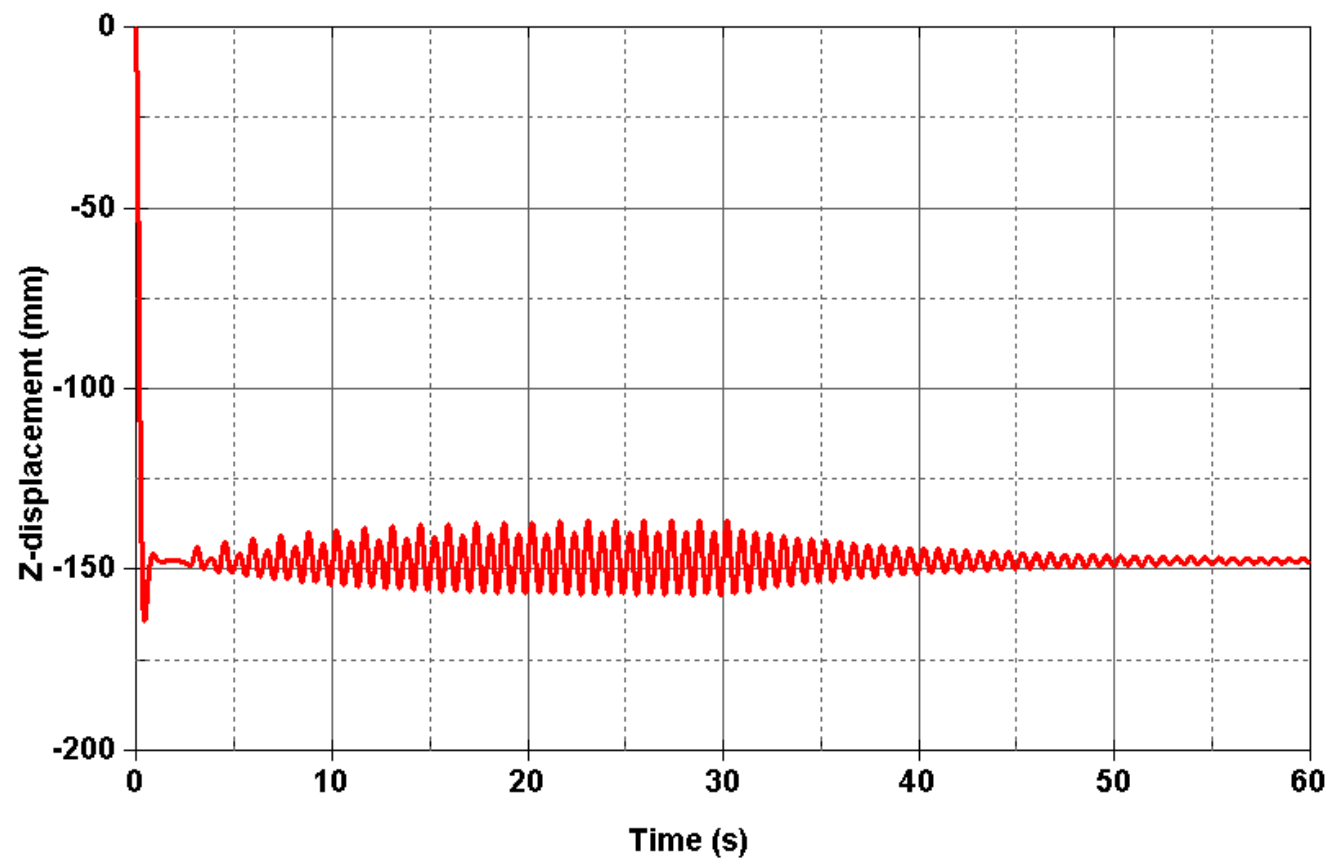

Figure 5-11: Vibration history of the cantilever tip in $\mathrm{Z}$ direction caused by passage of twenty trucks (a) simulation without structural damping (b) with $1 \%$ of critical damping

Another, more extreme case was simulated with trucks passing next to each other on two travel lanes with a head wind blowing at a speed of $10 \mathrm{mph}$. The loading curves were built to represent 
a group of six trucks, three trucks in two rows. The curve representing vibration of the sign tip in this case is shown in Figure 5-12. Again, a one way coupling did not allow for full FSI which might have triggered larger amplitude vibrations.

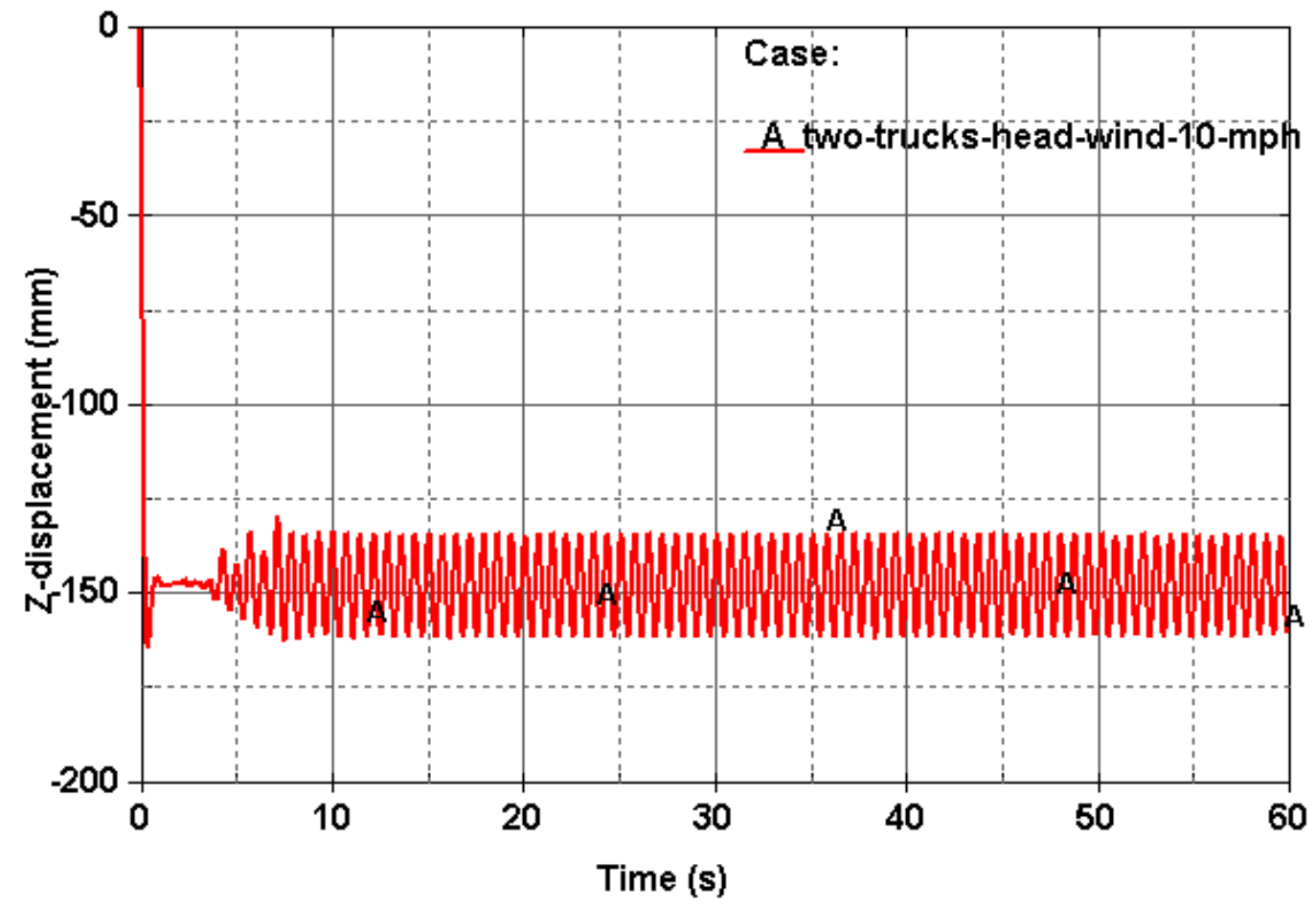

Figure 5-12: Vibration history of the cantilever tip in $\mathrm{Z}$ direction caused by passage of six trucks and $10 \mathrm{mph}$ head wind

\section{Summary}

CFD with unsteady RANS analysis is a powerful tool for studying flows around objects moving with respect to each other. Performing full scale or even laboratory scale experiments of such systems creates a lot of difficulties. However, multiple case scenarios can be analysed using CFD for a small incremental cost.

Results presented here indicate that the calculated pressure histories of the gusts caused by trucks passing under a Variable Message Sign resemble historical data from experiments. A nonstreamlined truck can exert as much as $75 \%$ higher pressures on the sign than a streamlined truck with a flow diverter over the cabin. Close to linear dependencies of maximum pressures on the VMS vs truck speeds were obtained. For the streamlined truck the maximum pressure grew from $20 \mathrm{~Pa}$ to $60 \mathrm{~Pa}$ with the increase of speed from $40 \mathrm{mph}$ to $70 \mathrm{mph}$. A linear dependency was also found between the maximum pressures and the height of the sign above the ground. The maximum pressure on the front panel dropped from $124 \mathrm{~Pa}$ to about $75 \mathrm{~Pa}$ with a sign height increase from $18 \mathrm{ft}$ to $20 \mathrm{ft}$. The calculations also show that the presence of $10 \mathrm{mph}$ head wind and multiple trucks under the sign can increase the maximum pressure up to threefold. 
Pressure histories for two truck shapes, four velocities, and three sign heights were analyzed. Different locations of the truck under the sign were also considered. CFD provided pressure curve estimates that agree reasonably well with experimental data in terms of the shape and the level of the pressure variation.

The mass and stiffness of the sign box were not calibrated and that may influence some of the natural frequencies, however it shouldn't significantly change the observed trends.

One way coupling between the CFD and CSM software did not indicate any cases leading to excessive vibrations. The analyzed worst case scenario with 20 consecutive trucks with constant space between them is unlikely to happen in reality. Thus, the analysis conducted so far indicates that the source of excessive vibrations in the sign may potentially come from the combined interaction between vibrations induced by natural wind gusts and the truck passage.

\section{Acknowledgements}

The funding for this project came from the Hydraulics Research Program at the Turner-Fairbank Highway Research Center, through Interagency Agreement Number 693JJ318N300045 between DOT and DOE, and the work was performed under DOE's contract with UChicago Argonne, LLC, contract no. DE-ACo2-06CH11357.

\section{References}

[1] Manual on Uniform Traffic Control Devices for Streets and Highways, https://mutcd.fhwa.dot.gov/ (last accessed: 07/11/2019)

[2] Consolazio, G. R., Johns, K. W. and Dexter, R. J., (1998) Fatigue Performance of Variable Message Sign \& Luminaire Support Structures, Volume 1 Fatigue related wind loads on highway support structures. Final Report, Lehigh University; Rutgers University; University of Minnesota; New Jersey Dept. of Transportation

[3] Fouad, F. H., Calvert, E. A., Nunez, E., (2003) NCHRP Report 494: Structural Support for Highway Signs, Luminaires, and Traffic Signals. Transportation Research Board, National Research Council, Washington, DC

[4] AASHTO, 2013, Standard Specifications for Structural Supports for Highway Signs, Luminaires, and Traffic Signals, American Association of State Highway Transportation Officials, Washington, DC

[5] AASHTO 2001, Standard Specifications for Structural Supports for Highway Signs, Luminaires, and Traffic Signals, American Association of State Highway Transportation Officials, Washington, DC

[6] Creamer B.M., Frank K.H., and Klingner R.E., (1979) "Fatigue Loading of Cantilever Sign Structures from Truck Wind Gusts.” Report No. FHWA/TX-79/10+209-1F, Center for Highway Research, The University of Texas at Austin 
[7] Edwards J.A., and Bingham W.L., (1984) "Deflection Criteria for Wind Induced Vibrations in Cantilever Highway Sign Structures.” Report No. FHWA/NC/84-001, Center for Transportation Engineering Studies, North Carolina State University

[8] Cook, R. A., Bloomquist D., Agosta A.M., and Taylor K.F., (1996), "Wind Load Data for Variable Message Signs.” Report No. FL/DOT/RMC/0728-9488, Engineering and Industrial Experiment Station, University of Florida

[9] Cook R.A., Bloomquist D., Agosta A.M. (1997)2 "Truck Induced Dynamic Wind Loads on Variable Message Signs." Transportation Research Board, Paper No. 970244, 187-193

[10] DeSantis P.V., Haig P.E, (1996) "Unanticipated Loading Causes Highway Sign Failure", ANSYS Convention, 3.99-3.108

[11] Kaczinski, M.R., Dexter, R.J. and Van Dien, J.P. (1998) "Fatigue Design of Cantilevered Signal, Sign, and Light Supports." NCHRP Report 412, Transportation Research Board, Washington, D.C

[12] Dexter R.J., Ricker M.J., (2002), "Fatigue-Resistant Design of Cantilevered Signal, Sign, and Light Supports." NCHRP Report 469, University of Minnesota, Minneapolis, MN

[13] Ruck, B., and Lichtneger, P., (2014) "Wind loads on flat boards and walls induced by passing vehicles," Symposium on Laser Methods in Flow Measurement, Karlsruhe, Germany, September 9-11, 2014, and related data: https://www.windforschung.de/vipas1.htm 


\section{Argonne}

Nuclear Science and Engineering Division

Argonne National Laboratory

9700 South Cass Avenue

Argonne, IL 60439-4815

www.anl.gov

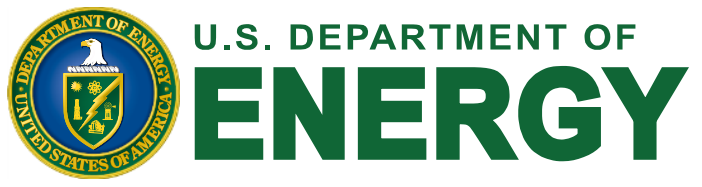

Argonne National Laboratory is a U.S. Department of Energy laboratory managed by UChicago Argonne, LLC

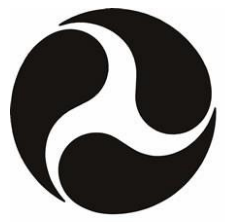

\section{U.S. Department of Transportation Federal Highway Administration}

